\title{
LAS NUEVASTENDENCIAS DE SEPARACIÓN IGLESIA-ESTADO EN LA JURISPRUDENCIA ESTADOUNIDENSE
}

\author{
EUGENIA RELAÑO PASTOR
}

Profesora Ayudante

Universidad Complutense de Madrid 


\section{SUMARIO}

1. Introducción; 2. La protección de la libertad religiosa en la Primera ENMIENDA. 2.1. Consideraciones preliminares. 2.2. La libertad religiosa en las dos cláusulas de la Primera Enmienda; 3. LA RELACIÓN COMPLEJA ENTRE LAS CLÁUSULAS dE la Primera ENMIENDA; 4. UNA REVISIÓN dE LA CLÁUSULA de No ESTABLECIMIENTO: MitCHeLl V. HeLmS y SANTA Fe v. Doe. 4.1. El acomodo de las creencias religiosas en la cláusula de no establecimiento. 4.2. Cuando la neutralidad es enemiga de la separación. 4.2.1. Las consecuencias del principio de neutralidad: Mitchell v. Helms. 4.2.1.1. Análisis de los fundamentos juridicos. 4.2.1.2 Los efectos de Mitchell v. Helms. 4.2.2. Los límites de la libertad religiosa: Santa Fe Independent School District v. Doe, 4.2.2.1. Antecedentes y precedentes de Santa Fe. 4.2.2.2. Análisis de Santa Fe v. Doe. 4.2.2.3. La influencia posterior de Santa Fe; 5. ConCLUSIÓN: LA POLÉMICA CONTINÚA. 


\title{
LAS NUEVAS TENDENCIAS DE SEPARACIÓN IGLESIA-ESTADO EN LA JURISPRUDENCIA ESTADOUNIDENSE
}

\author{
POR \\ EUGENIA RELAÑO PASTOR \\ Profesora Ayudante \\ Universidad Complutense de Madrid
}

\section{INTRODUCCIÓN}

Basta observar el panorama de Estados Unidos para descubrir la importancia y valor que se otorga a la religión y a la diversidad religiosa en este país. Las cerca de 500.000 iglesias, templos y mezquitas, de todas formas y tamaños, salpican el paisaje americano y.no pasan desapercibidas ni para los políticos ni para los juristas'. De hecho, los últimos cincuenta años han sido el medio siglo más religioso de la historia de la nación ame-

1 El presidente Bill Clinton tuvo ocasión de pronunciar un discurso titulado «La libertad religiosa en Norteamérica» en la escuela secundaria James Madison de Virginia el 12 de junio de 1995. Destacó, entre otras, las siguientes afirmaciones: «(...) Una de las cosas de las que me siento más orgulloso como Presidente de los Estados Unidos ha sido la de sancionar con mi firma la 'Ley para la Restauración de la Libertad Religiosa' de 1993 (...) Nuestros Fundadores comprendieron que la libertad religiosa era básicamente una moneda de dos lados. La Constitución protegía el libre ejercicio de la religión, pero prohibía el establecimiento de una religión. Ese equilibrio cuidadoso significa algo específicamente estadounidense. Ese es el genio de la Primera Enmienda. No nos hace un país sin religión, como han sugerido algunos. Nos ha hecho el país más reli- 
ricana, a juzgar por los censos y demás datos citados por Roger Finke y Rodney Stark en The Churching of America ${ }^{2}$. Y concretando algo más, la religión, que ha desempeñado un papel central en la vida jurídica y política de los Estados Unidos desde tiempos coloniales, adquiere una extraordinaria vitalidad $y$ controversia en la última década de los noventa del siglo $\mathrm{XX}$, como consecuencia de las decisiones más polémicas del Tribunal Supremo en materia de libertad religiosa.

Los principios rectores que sustenta la definición de libertad religiosa quedaban establecidos en las palabras iniciales de la Primera Enmienda: «El Congreso no elaborará ninguna ley respecto a un establecimiento de religión alguna, o prohibiendo su libre ejercicion. La relación, alcance y juego de las dos cláusulas, por el contrario, han ido tomando forma mediante el impulso y la labor de la jurisprudencia, de la doctrina y de la intervención legislativa. A lo largo de los años noventa del siglo pasado, el Tribunal Supremo batalló con el Congreso el alcance de la cláusula de libre ejercicio, al tiempo que redefinía y daba un giro copernicano a la cláusula de no establecimiento.

En sólo dos años -1999-2000 - el Tribunal Supremo abandonó un paradigma jurídico de trato específico hacia lo religioso, que había alentado una interpretación favorable del principio de separación IglesiaEstado, para sumarse a las doctrinas igualitaristas, las cuales, tratando de nivelar la religión a cualquier otra actividad, plantean hoy en día dudas sobre la posible vulneración del principio de neutralidad. Este cambio de paradigma se ha ido realizando de manera paulatina hasta verse confirmado con dos sentencias ya históricas por sus efectos y su trascendencia: Mitchell v. Helms y Santa Fe Independent School District v. Doe ${ }^{3}$. Con la

gioso del mundo (...) $Y$ este viejo debate que iniciaron Madison y Jefferson hace 200 años, todavía da vueltas hoy, acerca de lo que se puede y no se puede hacer en las escuelas (...) lo diré nuevamente, la Primera Enmienda no convierte nuestras escuelas en zonas libres de religión (...) hay quienes creen que nuestras escuelas deberían ser neutrales con respecto a los valores y que la religión no tiene cabida en las escuelas. Esta afirmación interpreta erróneamente la idea de separación/muro Iglesia y Estado. Estos no son los muros de la escuela (...) Lo que deseo decir al pueblo estadounidense y lo que quiero decirles a ustedes hoy aquí es que James Madison y Thomas Jefferson no tuvieron la intención de clavar una estaca en el corazón de la religión y sacarla de nuestra vida pública. Lo que se propusieron hacer fue crear un sistema por el cuál pudiéramos traer la religión a nuestra vida pública $y$ a nuestra privada sin que ninguno de nosotros le dijera al otro qué hacer (...)n, cursiva mía. Jersey (1993).

2 R. FINKE y R. STARK, The Churching of America, Rutgers University Press, New

3 Mitchell v. Helms, 120 S.Ct 2530 (2000) y Santa Fe Independent School District v. Doe, 530 U.S. 290 (2000). 
primera se consagra lo que Profesor Laycock ha llamado" formal neutrality" entre "lo religioso" y "lo no-religioso", anulando los precedentes sobre las ayudas a los centros educativos de la era Burger; con la segunda, el Tribunal Supremo confirma la inconstitucionalidad de los "government religious messages», avivando la polémica sobre el lugar que ocupa los valores religiosos judeo-cristianos en la vida pública norteamericana.

A continuación se presenta un estudio de la relación histórica de las. dos cláusulas de la Primera Enmienda y una explicación del cambio operado en la cláusula de no establecimiento a luz de las dos citadas decisiones del Tribunal Supremo, ya históricas. Clinton anunció literalmente "es. posible que la Primera Enmienda sea imperfecta, pero es lo más aproximado a la perfección que haya sido creado jamás por sociedad humana alguna para la promoción de la religión y los valores religiosos» 4 . El problema, por lo tanto, residirá en hacer perfecta la protección jurídica de la libertad religiosa sin desnaturalizar la promoción de la religión y la identidad de los valores religiosos.

\section{LA PROTECCIÓN DE LA LIBERTAD RELIGIOSA EN LA PRIMERA ENMIENDA}

\subsection{Consideraciones preliminares}

La idea de la libertad religiosa ha estado presente en la conciencia politica y en la vida pública americana desde tiempos coloniales $y$, muestra de ello, son las alusiones en textos estatales como la Declaración de derechos de Massachussets de $1780^{5}$ o en la Declaración de derechos de Virginia de $1776^{6}$. En el periodo que media entre 1776 y la aprobación de la Primera Enmienda en 1791 se amplía el concepto de tolerancia, heredado 1995.

4 Bill Clinton, "La libertad religiosa en Norteamérica», Virginia, 12 de junio de

5 En su artículo 16 establecía que «la libertad de prensa es esencial para garantizar la libertad del. Estado, y por consiguiente no debe restringirse en este». Vid. $M$. ARTOLA, Los Derechos del Hombre, Alianza, Madrid, (1986) pág. 82.

6 En su artículo 16 se recogia la siguiente afirmación: que la religión o el deber que tenemos para nuestro creador y su ejercicio sólo puede regirse por la razón y la convicción, y nunca mediante la fuerza o la violencia. Todos los hombres tienen igual derecho al libre ejercicio de la religión de acuerdo a los dictados de su conciencia«. Ibíd. La batalla victoriosa para terminar con el establecimiento en Virginia y el reconocimiento de la libertad religiosa es un capítulo esencial en la historia de la libertad religiosa en 
de los escritos de John Locke, al término de "libre ejercicio" que dificultaba el compromiso o identificación de las distintas iglesias con ciertas colonias. De hecho, en sus orígenes, la mayoría de las colonias mantuvieron religiones oficiales o cuasi-oficiales: las colonias del norte (Massachussets, Connecticut y New Hampshire) eran en su mayoría Congregacionalistas; las colonias del Sur (Virginia, Maryland, Carolina del Norte, Carolina del Sur y Georgia) tenian la iglesia Anglicana como oficial; y las del Centro (Pennsylvania, Rhode Island, Delaware y New Jersey) nunca tuvieron religión oficial y disfrutaron de mayor tolerancia religiosa7.

La Primera Enmienda pertenece al grupo de enmiendas, de la primera a la octava, que garantiza derechos individuales frente a la intervención del Gobierno federal ${ }^{8}$ y son conocidas como el Bill of Rights. Los estados miembros, salvo que la Constitución se lo retire expresamente, pueden regular aquellas materias que les atribuyan sus respectivas Constituciones. Como la Primera Enmienda era de aplicación federal, el Gobierno federal no era competente para regular la libertad religiosa en los estados miembros $y$ éstos, obedeciendo a sus respectivas constituciones estatales, podían limitar el ejercicio de la libertad religiosa en sus territorios sin vulnerar por ello

Norteamérica. Madison y Jefferson desempeñaron un papel decisivo con la ayuda de los baptistas (John Leland), presbiterianos, cuáqueros y otras religiones "disidentes" de la Virginia Anglicana. El reavivamiento religioso del siglo XVIII, a menudo llamado el Gran Despertar (1728-1790), creó nuevas formas de expresión religiosa y creencias que influyeron en el desarrollo de la libertad religiosa en todas las colonias, vid. C. H. HAYNES, "Las raices de la libertad religiosa norteamericana", documento del Centro de la Primera Enmienda del Freedom Forum, Universidad de Vanderbilt, Nashville, Tennessee.

7 Existen dos trabajos generales de excelente calidad para el estudio de los origenes de la libertad religiosa en Norteamérica: M. MCCONNELL, "The Origins and Historical Understanding of Free Exercise of Religion", Harvard Law Journal, vol. 103 (1990) pp. 1416-1517 y J. T. NOONAN, The Lustre of Our Country. The American Experience of Religious Freedom, University of California Press, Berkeley (1998). Para un análisis más especifico por colonias, vid: J. KNIGHT, Orthodoxies to Massachussets: rereading American puritanism, Harvard University Press, Cambrigde (1994) y E. S. GAUSTAD (ed.), A Documentary history of Religion in America to the Civil War, Eerdemans, Grand Rapids, Michigan (1982). Para una descripción breve y completa, vid. A. M. VEGA y J. PÉREZ, "Una aproximación al concepto jurídico de religión en la jurisprudencia norteamericana", Revista General de Derecho Canónico y de Derecho Eclesiástico del Estado, núm. 1, www.iustel.com

8 Las enmiendas novena y décima se limitaban a circunscribir las competencias que corresponden al Gobierno federal y a establecer que los poderes que la Constitución no delega a los Estados Unidos ni prohíbe a los Estados, quedan reservados exclusivamente a los Estados respectivamente o al pueblo. 
la Primera Enmienda9. El alcance y contenido de la libertad religiosa era, por lo tanto, variable entre los distintos estados. Por esto, la enmienda no afectó a las iglesias oficiales o quasi-oficiales de los Estados ${ }^{10}$, ni impidió prácticas discriminatorias por motivos religiosos ${ }^{11}$.

En 1803, en la sentencia que decidió el caso Marbury v. Madison ${ }^{12}$, el Tribunal Supremo estableció la vinculación de todos los Estados a la Constitución y la nulidad de toda ley estatal contraria a la misma. Tras la Guerra civil norteamericana, se aprueba la decimocuarta enmienda en 1868 , por la que todos los estados federados quedaban vinculados directamente a los derechos contenidos en las diez primeras enmiendas. El siguiente acontecimiento juridico se produce en 1940 y se conoce en la doctrina norteamericana como la "doctrina de la incorporación", por la cual, el Bill of Rights, que afectaba inicialmente al legislador federal, vinculaba a todas y cada una de las normativas estatales. Esta doctrina se inicia con el caso Palko v. Connecticut ${ }^{14}$ relativo a la libertad de expresión y se extiende a todas las libertades, entre ellas, la religiosa. El efecto inmediato sobre la libertad religiosa fue el de "desmembrar" la hasta ahora garantía unitaria de la libertad religiosa en dos "cláusulas": la Free Exercise o cláusula de libre ejercicio y la Establishment Clause o cláusula de no establecimiento ${ }^{15}$. A partir de entonces, se verifica una paulatina uniformización de las garantías para la libertad religiosa en todo el territorio federal. Hasta entonces existían constituciones estatales en las que el derecho a la libertad religiosa estaba limitado y determinadas confesiones gozaban de un estatus privilegiado (Arizona, Arkansas, Colorado,

9 En opinión del Juez Stewart en la sentencia que resolvió el caso School Discrit of Abington v. Schempp, 309-310 (1963), la primera enmienda fue adoptada con el objeto de limitar el poder del nuevo Gobierno federal y evitar que se pudiera establecer un religión oficial o interferir en las religiones ya establecidas.

10 Me refiero a las establecidas en los Estados de Massachussets, Connecticut y Nueva Hampshire, en las cuales, los ciudadanos pagaban un impuesto religioso para financiar la Iglesia congregacionalista.

11 Por ejemplo, la exclusión de los cargos públicos de los católicos en el estado de Nueva York o Nueva Hamsphire.

12 Marbury v. Madison, 1 Granch 137 (1803).

13 A partir de ahora, TS.

14 Palko v. Connecticut, 301 U.S 319 (1937).

15 Vid. R: Palomino, Las Objeciones de conciencia. Conflictos entre conciencia $y$ ley en el derecho norteamericano, Editorial Montecorvo, S. A. Madrid (1994) pp. 37-38. 
Delaware, Florida, Illinois, Indiana y Kansas) y en otras, en las que, además de la libertad religiosa, se incluia la Establishment Clause (Louisiana, Nueva Jersey y Utah). 16

\subsection{La libertad religiosa en las dos cláusulas de la Primera Enmienda}

Suele aceptarse que la Primera Enmienda contiene dos cláusulas: la Free Exercise Clause, por la que se prohibe cualquier ley o acto administrativo que impida el libre ejercicio de la religión y la Establishment Clause, que impide al Congreso federal aprobar cualquier ley adoptando una religión como oficial, y que terminaría por entenderse, por acción del TS, como un mandato constitucional de completa separación Iglesia $y$ Estado ${ }^{17}$. La relación entre las dos cláusulas y los criterios para la interpretación de ambas han evolucionado a lo largo de la segunda mitad del siglo $\mathrm{XX}$.

1. En una primera etapa, una vez que entró en vigor la decimocuarta enmienda, el primer caso por el que se aplicó la cláusula de libre ejercicio a los Estados, a luz de la doctrina de la incorporación, fue Cantwell v. Connecticut ${ }^{18}$. En el caso Cantwell se impugnaba una ley del Estado de Connecticut que impedía solicitar dinero u objetos de valor para fines filantrópicos, religiosos o benéficos a personas ajenas a tales organizaciones, salvo la autorización de la Secretary of Public Welfare Council. El Tribunal Supremo invalidó la ley estatal porque atentaba contra la libertad religiosa de la Primera Enmienda. Las tres consecuencias inmediatas fueron las siguientes: en primer lugar, que los estados no podían promulgar ninguna

16 Vid. O. CELADOR, Estatuto jurídico de las confesiones religiosas en el ordenamiento jurídico estadounidense, Dykinson, Madrid (1998) pp. 44-45.

17 Esta afirmación no es aceptada por la doctrina por absoluta unanimidad. M. A. Glendon sostiene que las dos cláusulas fueron una invención del TS a lo largo de del siglo XX, en concreto, a partir de 1940, cuando se decide reforzar la separación Iglesiaestado. Los autores sostienen que la única "cláusula" es la de la libertad religiosa, respecto de la cual la establishment no es sino un instrumento de garantía, vid. M. A. GLENDON y R. F. YANeS en "Structural Free Exercise», Michigan Law Review, núm. 90 (1991) pp. 477-550.

18 Cantwell v. Connecticut, 310 U.S 296, 303 (1940). Para una jurisprudencia decidida a la luz de la cláusula decimocuarta, vid. el artículo de K. T. LASH, uThe Second Adoption of the Free Exercise Clause: Religious Exemptions under the Fourteenth Amendment, Northwestern University Law Review, núm. 88 (1994) pp. 1106-1163 y el análisis de G. MORÁN, La protección jurídica de la libertad religiosa en USA, Monografías de la Universidad de Santiago de Compostela, núm. 139 (1989) pp. 41-43. 
norma que infringiera el libre ejercicio de la religión y de hacerlo, el TS determinaría cuándo se había producido la infracción; en segundo lugar, la decimocuarta enmienda protegeria las libertades de pensamiento, creencia o religión; y en tercer lugar, el derecho de libertad religiosa adquiriría, a partir de esta sentencia, la consideración de derecho fundamental, tanto en el plano estatal como en federal.

En esta primera etapa, cristalizó también la interpretación de la cláusula de no establecimiento. Desde mediados del siglo XIX se había producido un importante incremento de la enseñanza pública en los Estados Unidos, al tiempo que comenzaban las primeras discusiones sobre el papel de la religión en dichas escuelas ${ }^{19}$. A pesar de la existencia de un movimiento social de corte anticatólico, entre 1875 y 1876, que propuso una enmienda a la Constitución federal para evitar cualquier ayuda estatal a las escuelas privadas religiosas, no se generó ni jurisprudencia ni doctrina sobre el alcance y los límites de la cláusula de no establecimiento 20 . De modo que cuando elTS elaboró la interpretación de esta cláusula, después de la Segunda Guerra Mundial, lo hiciera como si no hubieran existido antecedentes 21 .

En Everson v. Board of Education 22 en 1947 se eleva a principio constitucional la separación de las iglesias y el Estado y se incorpora la vinculación de la cláusula de no establecimiento a los Estados federados ${ }^{23}$. EITS se pronunció sobre la constitucionalidad de una ley del Estado de Nueva Jersey por la que se otorgaba financiación pública a las escuelas religiosas

19 Vid. C. F. KAESTLE (ed.) Pillars of the Republic: Common Schools and American Society, 1780-1860, 1983 y D. RaviTCH, The Great School Wars, New York City, 1805-1973.

20 J. H.CHOPER, "The Establishment Clause and Aid to Parochial Schools", California Law Review, vol. 75 pp. 5-24 (1987).

21 N. Feldman, "From Liberty to Equality: The transformation of the Establishment Clausen, California Law Review, vol. 90 (2002) pág. 680.

22 Everson v. Board of Education, 330 U.S. 1 (1947).

23 En Everson y a partir de esta sentencia, el TS asume la incorporación de la Establishment a los Estados. Sin embargo, se ha criticado la inoportunidad de extender el contenido de esta cláusula a los estados, vid. A. R. AMAR, The Bill of Rights: creation and Reconstruction, 1998. Por su lado, K. T. LASH sostiene la teoria de la incorporación en su trabajo, "The Second Adoption of the Establishment Clause: the rise of the Nonestablishment Principle", Arizona State Law Journal, vol. 27 (1995) pp. 1085-1154, utilizando la intención originaria de los Framers: estos dirigieron la cláusula de no establecimiento a proteger la libertad de conciencia frente a cualquier intento de coerción y proteger la conciencia del individuo frente abusos de los Estado, por lo tanto, extendieron originariamente a los Estados la cláusula de no establecimiento, tal y como se entendía a nivel federal. También $\mathrm{D}$. O. CONKLE elabora la teoría de la incorporación de 
en materia de transporte escolar. EI TS consideró inconstitucional que se destinase parte de los impuestos del Estado a las escuelas privadas de titularidad religiosa 24 . A partir de esta sentencia, la cláusula de no establecimiento se aplica a los Estados y, por tanto, se uniformiza la neutralidad en el ámbito estatal y federal. El Juez Black apunta que la incorporación de la cláusula a los Estados requiere una explicación del objetivo que la misma persigue, que no es otro que la eliminación de las persecuciones religiosas, importadas desde Europa 25 . En su opinión, América no se ha salvado de esta epidemia y muestra de ello son las numerosas confesionalidades de estados que sostienen y asisten a determinadas iglesias ${ }^{26}$. Con la analogía que hace el Juez Black entre la situación en 1947 y la que existía en la época de los framers - considerada desacertada por parte de la literatura jurídica norteamericana - se consolida la orientación de la cláusula de no establecimiento: la protección de los grupos religiosos frente a persecuciones e interferencias del Gobierno.

En general, en esta primera etapa, el TS no tuvo ocasión de abordar la problemática de las exenciones basadas en la Primera Enmienda (free exercise exemptions) puesto que era el momento de la expansión de la cláusula de no establecimiento al amparo de las escuelas de interpretación enfrentadas 27 . De un lado, los partidarios de "la no preferencia» o el "acomodo", según los cuales el Estado puede cooperar con las confesio-

la Establishment Clause mediante la decimocuarta enmienda en un magnífico trabajo titulado, "Toward a General Theory of the Establishment Clause", Northwestern University Law Review, vol. 82 (1988) pp. 1113-1187.

24 Aunque elTribunal mantuvo el programa objeto del litigio por una decisión de 5 a 4, con las opiniones contrarias de los Jueces Jackson y Rutledge, en la sentencia se diseñó la teoría de la separación, por la que cualquier ayuda directa gubernamental a escuelas religiosas es inconstitucional al amparo de la Primera Enmienda.

25 Everson, cit. 9.

26 En palabras del Juez Black: «dissenters were persecuted because they steadfastly persisted in worshipping God only as their own consciences dictated (...) they were also compelled to pay tithes and taxes to support government-sponsored churches whose ministers preached inflammatory sermons designed to strengthen and consolidate the established faith by generating a burning hatred against dissenters», Everson, cit. 10-11. El análisis histórico que hace el Juez sobre el nacimiento de la idea de libertad de conciencia como consecuencia de las persecuciones de grupos religiosos en tierras americanas parece algo exagerado. Basta repasar los discursos de James Madison para comprobar que las menciones a las persecuciones adoptan un tono mas retórico que descriptivo. Vid. «Memorial and Remonstrance Against Religious Assessments to the Honourable the General Assembly of the Commonwealth of Virginia» en R. A. RUTLAND (ed.) The Papers of James Madison, (1973) pág. 299.

27 Vid. R. Palomino, op. cit. pág. 40. 
nes religiosas, siempre y cuando, se realice en un plano de igualdad y no excluya a ningún grupo. De otro lado, los partidarios de la estricta teoría separatista, que tiene sus orígenes en Jefferson y Madison 28 y partidarios de la no financiación ni colaboración del Estado con la religión en ningún supuesto.

2. La segunda etapa se desarrolla en un contexto político-social a favor de los derechos civiles, los derechos individuales y la defensa de las minorias. Es el momento en el que se consolida el llamado Civil Rights Movement que sitúa el principio de no- discriminación como la problemática jurídica central para el derecho constitucional. Por lo tanto, los argumentos a favor de la igualdad religiosa cobran especial relevancia, al tiempo que la religión se convierte en un elemento identificador para los grupos de color 29 . Para la interpretación de la cláusula de libre ejercicio se adopta el criterio del compelling state interest por el que se establece que «la conducta religiosamente motivada sólo puede ser restringida cuando frente a

28 Thomas Jefferson, heredero de la llustración, sostuvo que la integridad del Gobierno quedaría intacta levantando lo que él denominó "wall of separation" entre la Iglesia y el Estado. Esta división era esencial para preservar la autonomía de la Iglesia y del Estado. James Madison compartía este análisis aunque desde un punto de vista más permisivo con las instituciones religiosas. Como apunta G. Morán, la concepción sobre la libertad religiosa de Jefferson parece más documentada que la de Madison. La idea del "wall of separation" no fue originaria de Jefferson sino de Roger Williams que fue el primer gran defensor de la libertad religiosa en las colonias inglesas de América del Norte, en G. MORÁN, op. cit. pág. 17. Para una semblanza de Jefferson, vid. J. MARTíNEZTORRÓN, "Thomas Jefferson" en R. DOMINGO (ed.), Juristas Universales, vol. III, Marcial Pons, Madrid (2004) (en prensa). Vid. los siguientes artículos sobre el tema: S. G. GEY, "Why is Religion Special? Reconsidering the Accommodation of Religion under the Religion Clauses of the First Amendment», University of Pittsburgh Law Review, núm. 52 (1990) pp. 75-127; J. H. HUTSON, "The Creation of the Constitution: the Integrity of the Documentary Record", Texas Law Review núm. 65 (1986) pp. 1-32; M. MCCONNELL, «The Origins and Historical Understanding of Free Exercise of Religion", Harvard Law Review vol. 103(1990) pp. 1409-1483; y el libro de J.T. NOONAN Jr, The Lustre of our Country, the American Experience of Religious Freedom, University of California Press, cit., en especial, la primera parte: History pp. 41-179.

29 Es el momento en el que cobran fuerza las iglesias negras como un fenómeno nacional de carácter político. Entonces, la religión adquiere gran protagonismo en la identidad politica, quedando separadas las iglesias blancas de las negras. Estas últimas solicitan ayudas asistenciales al Gobierno federal debido a la situación de desventaja y segregación en la que se encuentran. Vid. W. B. CARTER, "Can this culture be saved? Another Affirmative Action Baby Reflects on Religious Freedom ", Columbia Law Review, vol. 95 (1995) pp. 507-509. Esta recensión sugiere la diferente actitud de las iglesias negras norteamericanas ante la libertad religiosa de la Primera Enmienda frente a la mantenida por las iglesias americanas de origen europeo. 
ella se alce un 'interés estatal prevalente» 30 . En cuanto a la cláusula de no establecimiento, la etapa anterior la había entendido como un mandato constitucional que impedía toda ayuda gubernamental y la separación estricta entre Estado e Iglesias. En 1971, recapitulando la jurisprudencia que había venido dictaminando cuándo una norma estatal o federal vulneraba el separatismo, el TS enuncia lo que llama "triple test" o el Lemon test, que formula las tres condiciones que debe cumplir una norma para ser compatible con la primera enmienda: 1) ha de perseguir un objetivo secular; 2) no puede producir como "efecto primario" el favorecimiento de la religión, $y$ 3) su aplicación no debe requerir un "enredamiento excesivo" (excessive entanglement) de los poderes públicos con la religión 31 .

3. En la tercera etapa, el Presidente Ronald Reagan nombra como Presidente del Tribunal Supremo a William Rehnquist en el lugar de Burger, voluntariamente retirado por razones de edad en 1986. Esta etapa se caracteriza por reducirse el radio de acción de la Establishment Clause, de modo que se amplían los casos en los que se contemplan la posibilidad de colaboración entre Gobierno y organizaciones religiosas para alcanzar objetivos comunes. Al mismo tiempo, las exenciones a la Free Exercise también experimentan un retroceso sobre todo a partir de la sentencia Smith, que restringe significativamente, en 1990, el radio de acción del balancing test y la posibilidad de invocar la doctrina del compelling state interest test queda circunscrita al campo de los unemployment compensation cases ${ }^{32}$. Después de la sentencia Smith, los grupos de presión religiosos promovieron ante el Congreso la Religious Freedom Restoration Act (Ley para la Restauración de la Libertad Religiosa) que se promulgó en 1993 con la intención de que los tribunales regresaran a la doctrina anterior a Smith, tal y como habia sido enunciada en el caso

30 Vid. el artículo de J. MARTÍNEZ-TORRÓN, "Separatismo y cooperación en la experiencia jurídica norteamericana" en Acuerdos del Estado Español con confesiones religiosas minoritarias. Actas del VII Congreso Internacional de Derecho Eclesiástico del Estado, Barcelona (1994) pp. 105-130 en pág. 113. La determinación del compelling state interest comprende en tres fases: en la primera, los tribunales valoran la sinceridad y la relevancia de las creencias y en qué medida la norma jurídica impide el ejercicio de la práctica de las mismas; en la segunda, los tribunales determinan si la efectividad de la norma tiene suficiente importancia para prevalecer sobre la libertad religiosa en litigio; y en tercer lugar, el Estado tiene que demostrar que no disponía de otras soluciones alternativas para la ejecución de la norma, en cuyo caso, habrá de emplear los medios menos lesivos que dificulten el ejercicio de este derecho.

31 Ibíd. pág. 114. El nombre del test proviene de la sentencia del TS donde fue enunciando: Lemon v. Kurtzman, 403 U.S. 602 (1971).

32 Vid. R. PALOMINO, op. cit, pág. 46. 
Sherbert v. Verner 33 en 1963, y de este modo instaurar de nuevo el balancing test. Posteriormente, el TS la declara inconstitucional en el caso City of Boerne v. Flores, Archbishop of S. Francisco 34 .

4. Tras la declaración de inconstitucionalidad de la RFRA, se abre una cuarta etapa tendente a paliar los efectos de dicha inconstitucionalidad y caracterizada por una actitud favorable a la protección de la libertad religiosa en las instancias de la legislatura federal y en las legislaturas estatales. Por un lado, el Congreso aprobó el 19 de julio de 1999 la ley Religious Liberty Protection Act (RLPA) ${ }^{35}$. A semejanza de la RFRA, el objetivo de esta ley fue el de reinstaurar el balancing test para las acciones del Gobierno que potencialmente pudiesen vulnerar la cláusula de la Free Exercise ${ }^{36}$. La RLPA sobrevivió a la oposición política en el Congreso pero no pasó el control en el Senado ${ }^{37}$. En el caso de haberse promulgado no hubiese sido suficiente para preservar la libertad religiosa de los ciudadanos de intrusiones por parte de las entidades estatales porque no revocaba la inmunidad de los Estados correspondiente a la undécima enmienda. Por lo tanto, las personas que hubiesen visto violado el derecho de libertad religiosa al amparo de RLPA no hubieran podido solicitar el resarcimiento de daños del Estado ni en tribunal federal ni estatal38. Por otro lado, aunque Boerne provocó la derogación de la RFRA, las legislaciones estatales no se han visto afectadas por las conclusiones a las que se llegaron con la sentencia Boerne. Al contrario, las conclusiones perjudiciales

34 City of Boerne v. Flores, Archbishop of S. Francisco, 117 S. Ct. 2157 (1997)

35 Religious Liberty Protection Act (RLPA), H.R. Rep. N 106-219, 1st of July, 1999.

36 Para un comentario de la RLPA, vid. J. W. ROCKWELL, "When Congress Answer Religion's Prayer: The Religious Liberty Protection act of 1999", Seton Hall Legislative Journal, vol. 25 (2001) pp. 135-166 y G. S, GILDIN, "A Blessing in disguise: Protecting Minority Faiths through State Religious Freedom Non-Restoration Acts", Harvard Journal of Law and Public Politics, núm. 23 (2000) pp. 411-507 en 418-419.

37 “Although the 1999 RLPA passed the House, it stalled in the United States Senate, mainly because some members of the civil rights community feared that religious adherents could invoke its protections to avoid application of state anti-discrimination statutes", D. SAVAGE y R. SIMON, "U.S. Restores Special Protections for Religious Groups" en L.A. Times, Sept. 23 (2000) pág. A1.

38 "Hence a person whose religion is burdened by a neural law passed by a state legislature could at most procure prospective relief for the violation of RLPA but could not recover damages for the harm caused prior to judgment", Ibíd. pág. 419. En atención: a esta controversia, el Tribunal Supremo apuntó en Alden v. Maine, 119 s. Ct. 2240 (1999): "Congress lacks the power under Article I of the Constitution to subject non-consenting states to suits for damages in their own court". 
para el ejercicio de la libertad religiosa que trajo la inconstitucionalidad de la RFRA alentó la búsqueda de esta protección mediante las legislaciones estatales, sin que por ello se haya invadido la primacía exclusiva en la interpretación de la Constitución que goza el Tribunal Supremo ${ }^{39}$. En general, todas las leyes para reinstaurar la libertad religiosa en los diferentes estados norteamericanos mantienen el compelling state interest con interesantes diferencias. En California, Michigan y Lousiana se introducen excepciones a estas leyes para que no se apliquen a grupos determinados, como a los reclusos. $Y$ en Texas no será aplicable la Texas Religious Freedom Restoration Act a las demandas que versen sobre derechos civiles o litigios administrativos sobre el suelo, temáticas de frecuentes controversias en el derecho del libertad religiosa. A pesar de estas restricciones, algunas legislaciones estatales han intentado elevar el nivel de protección de la libertad religiosa introduciendo una concepto amplio de "gravamen sobre la libertad religiosa" con la finalidad de evitar que los tribunales interpreten con demasiada severidad el contenido de gravamen, reduciendo la protección de la libertad religiosa 40 . Las legislaciones

39 El 24 de marzo de 1998, se pasó en Louisiana la Louisiana Religious Freedom Restoration Act, H.R. 167, 1998. En Nueva York, dos semanas después de Boerne, se intentó restaurar el compelling interest test en una ley sobre libertad religiosa, no prosperó $y$ se intentó una vez más el 17 de enero de 1999 (S. A05139 1999 Reg. Leg. Sess.). En 1998 y 1999, los parlamentarios de Maryland redactaron la Maryland Restoration Freedom Act (S. 674, 1999 Reg. Sess.). En New Jersey, se introdujo en el parlamento estatal la New Jersey Religious Freedom Act (A. 903, S. 321, 208th Leg. 1998); en Michigan, la Michigan Religious Freedom Act (H.R. 4376, 89th Leg., 1997 Reg. Sess.) y en Virginia, los parlamentarios introdujeron una ley para preservar la libertad religiosa mediante el strict scrutiny en todas las posibles infracciones de libertad religiosa (H.R. 1, 1998 Reg. Sess. Va. 1998). Religious Freedom Acts se han promulgado también en Georgia ( H.R. 1123, 20th Leg. Ga. 1999); Missouri, H.R. 1799, 2000 Reg. Sess. Mo. 2000); Oregon (H.R. 3469, 70th Leg., Reg. Sess. Or. 1999); Hawaii (H.B. 1696, 20th Leg. Sess. Ha. 1999); Indiana (H.B. 1264, 111th Gen. Ass., 2d Reg. Sess. Ind. 2000) y Oklahoma, S. B. 1162, 47th Leg. 2d Reg. Sess. Ok. 2000). En Alabama, los ciudadanos aprobaron una reforma parcial a la constitución estatal por la que se prohíbe menoscabar la libertad religiosa de la libertad religiosa a menos que el Estado demuestre un compelling interest que no puede ser satisfecho por otros medios alternativos menos lesivos (S. 604, 1998 Reg. Sess. Ala. 1998) y en New Mexico se pasó la Religious Freedom Restoration Act el 2 de febrero de 2000.

40 Merece la pena destacar algunos ejemplos. En el Arizona Religious Freedom Restorarion Act se especifica que el término "substantial burdens" excluye sólo a "de minimis, trivial or techinal burdens", Ariz. Rev. State. Ann. 41.1493-01E (1998) y en Alabama Religious Freedom Amendment, se elimina "substantial" delante de "burden". En Alabama, la protección de libertad religiosa se ha recogido en una reforma constitucional, previo referéndum, de modo que está protegida frente a cualquier ley emanada de las legislaturas estatales. Vid. T. C. BERG y F. MYERS, "The Alabama Religious Freedom Amendment: An interpretative guide", Cumberland Law Review, vol. 31(2000-2002) pp. 47-78. 
estatales para el mantenimiento de la libertad religiosa son el producto de un amplio debate en la ciudadanía sobre el equilibrio entre el orden público y las exigencias de protección de la libertad religiosa individual. Estos intentos legislativos derivan de la competencia de los Estados para resolver el debate sobre el conflicto de derechos, respetando, en todo caso, los mínimos establecidos en la Constitución federal. Incluso en Smith, el TS afirmó41 que el rechazo del strict scrutiny de la cláusula de libre ejercicio no deslegitimaba a los estados particulares para conceder exenciones por motivos religiosos a leyes neutrales. Al contrario, señalaba que con su decisión se abría la puerta para que el acomodo de las prácticas religiosas se hiciera mediante el proceso político. A diferencia de la RFRA, el proceso político estatal que opte por el strict scrutiny test para la libertad religiosa no significa interferencia alguna con las competencias del Tribunal Supremo 42 . Esta solución ha comenzado a llamarse la udoctrina de la deferencia” 43 o deference doctrine porque son los parlamentos políticos mediante su legislación los que podrá acomodar las exigencias derivadas del libre ejercicio de la religión aunque la cláusula de libre ejercicio no les obligue a ello.

Por último es preciso añadir que numerosos tribunales estatales, incluso con anterioridad a la RFRA44, han interpretado las cláusulas de Free Exercise de sus constituciones rechazando las conclusiones de Smith y aplicando el balancing test a las leyes neutrales de alcance general 45 . Al rechazar las conclusiones de Smith, los tribunales han querido destacar la dificultad de conciliar la libertad religiosa de una sociedad multireligiosa con los principios emanados del caso.

41 Employment Div v. Smith, 494 U.S. 872, 890 (1990).

42 Vid G. H. GILDIN, A Blessing in Disguise: ..., cit., pág. 422.

43 Esta doctrina ya la adelantaba M. A. GLENDON y R. F. YANES en "Structural Free Exercise", Michigan Law Review, núm. 90 (1991) pp. 477-550 en pág. 518.

44 Vid. People v. de Jonge, 501 N.W. 127 (Mich. 1993); State v. Hershberger, 462 N. W. 2d. 393 (Minn. 1990); First Covenant Church v. City of Seattle, 840 P. 2d 174 (Wash. 1992). Para un comentario más detallado, recomiendo: S. C. CARMELLA, "State Constitutional Protection of Religious Exercise: An Emerging Post-Smith Jurisprudence", Brigham Young University Law Review (1993) pp. 275-325.

45 Por ejemplo, el Tribunal Supremo de Ohio sostuvo el strict scrutiny en el caso de un prisionero de la religión nativa americana que se negaba a cortarse el pelo. El Tribunal alegó que se debía buscar la manera de eximir al recluso del código de disciplina del centro penitenciario: Humphrey v. Lane, 728 N. E. 2d. 1039 (Ohio 2000). En Wisconsin, el Tribunal Supremo eximió de llevar el triángulo reflectantes en los vehículos tradicionales a los propietarios Amish: State v. Miller, 549 N. W. 2d. 235 (Wis. 1996). 
Este recorrido histórico por la protección de la libertad religiosa no puede concluir sin mencionar las iniciativas del poder legislativo norteamericano que, en los últimos cuatro años, ha consolidado la protección de la libertad religiosa con dos acontecimientos jurídicos de especial relevancia: la Religious Land Use and Institutionalized Persons Act (RLUIPA) del año 2000 y la International Religious Freedom Act (IRFA) de 1998. Por la primera, se reestablece el compelling interest test para los casos que surjan en centros penitenciarios y para aquellos litigios en los que las normativas federales y estatales sobre el uso de tierras y propiedades interfiera con el ejercicio de la libertad religiosa46. Mediante la segunda, la IRFA, el Congreso norteamericano compromete la política exterior norteamericana con la protección de la libertad religiosa en el mundo. Se crea la Oficina de la Libertad Religiosa Internacional en el Departamento de Estado y la Comisión para la Libertad Religiosa Internacional, cuyo trabajo es preparar un informe anual de la situación de la libertad religiosa en el mundo con recomendaciones para el Congreso y el Presidente, el cual está obligado a considerar el informe anual y elaborar las oportunas directrices de política exterior norteamericana hacia los países que flagrantemente violan el derecho de libertad religiosa 47 .

46 “RLUIPA applies the compelling interest test to any state or local land use decision substantially burdening religion where the government program in question receives federal funds, where the burden on religion affects interstate commerce, or where the land use authority makes individualized assessments of proposed uses for the property involved", 42 U.S.C., 2000cc-a2 (C) (2000).

47 La incorporación de la protección de la libertad religiosa a la política exterior estadounidense constituye el paradigma de una protección internacional unilateral, en claro contraste con la multilateralidad de los esfuerzos de Naciones Unidas. En el último año, como consecuencia de los acontecimientos del 11 de septiembre, las sanciones a países que violan sistemáticamente la libertad religiosa se han mediatizado por razones geoestratégicas de la lucha internacional contra el terrorismo. Aunque no es lugar para mayores precisiones, recomiendo el trabajo de P. DANCHIN que analiza las repercusiones de los informes de la Comisión para la Libertad Religiosa Internacional, "U.S. Unilateralism and the International Protection of Religious Freedom: The Multilateral Alternative", Columbia Journal of Transnational Law, vol. 41 (2002) pp. 33-117. Para una crítica de la IRFA: N. J. STARR, "Who asked you?:The appropriateness of U.S. Leadership in promoting religious freedom worldwide", Vanderbilt Journal of Transnational Law, vol. $33(2000)$ pp. 987-1025 y S. WALES, "Remembering the persecuted: An analysis of the International Religious", Houston Journal of International Law, vol. 24 (2002) pp. 579-635. 


\section{La relación entre las dos cláusulas de la Primera Enmienda}

La Free Exercise prohíbe cualquier ley que impida el libre ejercicio de la religión, y la Establishment Clause prohibe que el Congreso federal adopte una religión como oficial o beneficie a unas religiones sobre otras. Con la cláusula de libre ejercicio, el Estado debe garantizar la libertad para creer y la libertad para actuar 48 , según unas determinadas creencias. Los ciudadanos disfrutan del derecho de libertad religiosa, derecho fundamental cuyo ejercicio sólo podrá ser restringido cuando entre en conflicto con la seguridad, la moral pública o con la cláusula de no establecimiento. Existen casos en los que se limita el libre ejercicio de la libertad religiosa por el alcance y el efecto de la cláusula de no establecimiento que han generado una doctrina interesante en torno al conflicto y al alcance de una y otra cláusula. La dificultad es diferenciar las situaciones en las que la cláusula de libre ejercicio obliga al poder público a respetar la libertad de actuar, al mismo tiempo que la cláusula de no establecimiento exige desconocer el ejercicio de esta libertad 49.

Ha sido complicado buscar un equilibrio y una respuesta a este conflicto. En general, se han propuesto dos soluciones 50 . Por un lado, hay quienes sostienen una interpretación conjunta de las dos cláusulas, por la cual, ambas serían entre sí complementarias y no excluyentes 51 , y otra

48 Desde el siglo pasado se hizo notar la diferencia entre libertad de creer y libertad de actuar. La primera es absoluta y la segunda es limitable por el Estado. Así lo establecía el TS en Reynolds v. United States, 98 U.S. 145, 1878. El problema, como apunta J. MARTÍNEZ-TORRÓN, "era precisar cuándo y en qué condiciones, la libertad de actuar puede ser objeto de restricción legítima (...) sobre la doctrina sentada en relación con la libertad de expresión, el libre ejercicio de la religión sólo resultaba coercible para evitar un 'peligro indudable y actual para la sociedad'", op. cit. pág. 113.

49 Los casos más paradigmáticos son los referidos a la educación pública. Los padres tienen el derecho, por un lado, a educar a sus hijos en la religión que crean conveniente, y los centros educativos públicos tienen el derecho a beneficiarse de ayudas estatales; mientras que por otro lado, la financiación estatal de una institución educativa que obedece a las demandas de los padres puede entenderse que viola la Establishment Clause.

50 Existe también una tercera solución que se ha conocido como la teoría de la "no coerción". Esta tercera teoria ha tenido poca acogida en elTS, en G. MORÁN, op. cit. pág. 34

51 "In the hand of Supreme Court, the task of the Establishment Clause is separate and independent of the Free Exercise Clause's protection of individual religious rights. Neither clause is subordinate or instrumental to the other. The religious rights of individuals and the ordering of relations between government and religion -while complementary, not contradictory- are altogether different enterprises", C. H. ESBECK, "The American System of Church-State Relations (and its bearing on church autonomy)" en G. ROBBERS (ed.) Church Autonomy. A Comparative Survey, Peter Lang GmbH, Berlin (2001) pp. 149-177 en pág. 161. 
parte de la doctrina aboga por la interpretación separada. Para aquellos defensores del primer enfoque, la cláusula de libre ejercicio protege el derecho a la libertad religiosa y la cláusula de no-establecimiento tiene un doble cometido52: defender la configuración pluralista de la sociedad norteamericana $y$, consecuentemente, proteger al grupo y el derecho a la libertad religiosa del individuo a través del grupo $53 \mathrm{y}$, como resultado, limitar el poder del Gobierno 54 .

Para el segundo sector de la doctrina es necesario una interpretación separada de ambas cláusulas 55 . El efecto inmediato sería que la interpretación extensiva de una cláusula restringiria el alcance de la otra (fuera pri-

52 Este doble cometido de la Establishment Clause puede obervarse en el caso Engel v. Vitale, 370 U.S. 421 en 431-433 (1962) y también el reciente Clinton v. City of New York, 118 S.CT. 2091, (1998) en la opinión del Juez Kennedy: " By denying governmental jurisdiction over inherently religious matters the Establishment Clause has the object of protecting religious liberty writ at large. Thus, the non-establishment principle is not an individual right from governmental intrusion, but a liberty (the blessing of which favour the entire body politic) to a government that may not intermeddle in inherently religious matters. This fundamental difference between the individual freedom that derives from a constitutional right and the polity-wide liberty that derives from constitutional structure has to be noted...", en 2109. Para un análisis teórico, vid. el trabajo de I. C. LUPU, "To Control faction and protect Liberty: A GeneralTheory of the Religion Clauses", Journal of Contemporary Legal Issues, núm 7 (1996) pág. 357-372.

53 Esta es la opinión de C. H. ESBECK en "Toward a General Theory of ChurchState Relations and the First Amendment" en Public Law Forum, núm. 4 (1985) pp. 325354 y en otro trabajo posterior, "The Establishment Clause as a structural restraint on governmental power" en lowa Law Review, vol. 84 (1998) pp. 1-113. También la opinión de G. V. BRADLEY, "Dogmatomachy: A 'privatisation' Theory of Religion Clauses Cases" en Saint Louis University Law Journal (1986) pp. 275-286; de S. D. SMITH, "Separation and the 'secular': Reconstructing the Disestablishment Decision", en Texas Law Review, núm. 67 (1989) pp. 955-970; y de D. H. DAVIS, "Resolving not to Resolve the Tension between the Establishment and the Free exercise Clauses" en Journal of Church of State, núm. 38 (1996) pág. 247 y ss.

54 Así lo manifiesta el Tribunal Supremo en los siguientes casos: United States v. Lopez, 514 U.S. en 549 y 552 (1995); Engel v. Vitale 370 U.S. 421 (1962) y en McCollum v. Board of Education 333 U.S. 203 (1948) en 201 núm. 2 y en 232-234 (opinión de Jackson). Véanse también los artículos: S. L. CARTER, "The Free Exercise Thereof", William and Mary Law Review, núm. 38, (1997) pp. 1627-1652 y S. SMITH, "The Rise and Fall of Religious Freedom in Constitutional Discourse" en University Paul Law Review, núm. 140 (1991) pp. 149- 74.

55 Vid. el symposium en el que se analiza las dos posturas: "Symposium, Confronting the Wall of Separation: A new dialogue between Law and Religion on the meaning of the First Amendment Law's Perspective of Religion and its view of the State", De Paul Law Review, vol. 42 (1992). También vid. J. CHOPER, "The Unpredictability of the Supreme Court's doctrine in Establishment Clauses cases", Wayne Law Review, vol. 43 (1997) pp. 1439-1449. 
mando la cláusula de libre ejercicio sobre la de no establecimiento o viceversa). En todo caso, la cláusula de no establecimiento se configura además como un principio de separación cuyo objetivo sería limitar el poder excesivo del Estado, asegurando - de este modo- la separación entre el Estado y la Religión ${ }^{56}$. En este sentido, tal y como se ha señalado anteriormente, el TS estableció en la sentencia que resolvió el caso Lemon v. Kurtzman ${ }^{57}$, los tres requisitos o las tres condiciones que deben cumplir las normas para no ser invalidadas a tenor de la cláusula de no establecimiento. Como apunta G. Morán, «en este caso no sólo se establece de modo formal el triple criterio jurisprudencial en cuestiones de asistencia estatal financiera, sino que se matiza el tercero de los criterios, endureciendo la postura de la jurisprudencia anterior, y consecuentemente, fortaleciendo el principio de separación" 58 . Si el Lemon test aclaró tímidamente la relación de las dos cláusulas puesto que el libre ejercicio de la religión quedaba protegido frente a cualquier norma estatal cuyo fundamento $y$ limite estaba, a su vez, en la cláusula de no establecimiento, el problema se presenta nuevamente con las leyes prima facie neutrales, que cumplen con los requisitos de la cláusula de no establecimiento pero que van en menoscabo del libre ejercicio de la libertad religiosa. En estos casos, la jurisprudencia sugiere recurrir a un balancing process que sopese los intereses en conflicto con el fin de decidir a cuál debe prestarse una atención preferente: la libertad religiosa o los intereses del Estado. La teoría del balancing test ${ }^{59}$ consta de tres fases: en la primera, el tribunal valora la sinceridad y la relevancia de la práctica religiosa y determina en qué grado la norma estatal vulnera el derecho de libertad religiosa60; en la segunda, mediante la teoría del compelling state interest, el tribunal determinará

56 A estos efectos, las dos sectores doctrinales coinciden, vid. C. H. ESBECK, "The Establishment Clause as a structural restraint...", cit. pp. 14-25.

57 Lemon v. Kurtzman, 403 U.S. 602 (1971). En este caso se invalidó un programa de subvención estatal a escuelas parroquiales católicas. La subvención iba dirigidas a salarios, libros de texto y material de instrucción de los profesores. Más del $20 \%$ del alumnado estatal asistía a las escuelas privadas, y la mayoría de éstos, a escuelas católicas. Vid. G. MORÁN, op. cit. pág. 50.

58 Vid. G. MORÁN, Ibíd.

59 Vid. la descripción de esta teoría en el trabajo de T. A. ALEINNIKOFF, "Constitutional Law in the age of balancing", Yale Law Journal, núm. 96 (1987) pp. 943-994.

60 Entre los casos más destacados en los que se ha aplicado están: Wisconsin v. Yoder, 406 U.S. 205 (1972); Shebert v. Verner, 374 U.S. 398 (1963). Vid. también las sentencias que recogen G. MORÁN y R. DESTRO "Sentencias decididas por el Tribunal Supremo norteamericano sobre la libertad religiosa en 1986, 1987, 1988" en Anuario de Derecho Eclesiástico Español, vol. V (1989) pp. 319-342 en pág. 321. 
cuando el interés del Estado prevalece sobre la libertad religiosa en el caso concreto; y en la tercera, es necesario demostrar que el Estado no dispone de ningún otro medio o solución (alternative means) para ejecutar sus normas, salvo el que limita el ejercicio de la libertad religiosa, para cuyo caso tendrá que utilizar los medios menos restrictivos (less restrictive means). ${ }^{61}$

Con el balancing test, el Estado amplía el alcance del derecho de libertad religiosa, puesto que no sólo protege las creencias religiosas sino también sus manifestaciones, que no pueden ser limitadas, ni directa ni indirectamente, a no ser que el Estado demuestre que colisiona con otro derecho o interés que debe prevalecer sobre el derecho de libertad religiosa. Como apunta R. Palomino, "el balancing test resulta provechoso, porque pone a los agentes jurídicos en contacto con la realidad, y facilita elementos de juicio cuando precisamente los dos valores gozan de protección. El inconveniente es su generalidad, su indefinición, la falta de criterios objetivos, que hacen de él una herramienta apta para el servicio de cualquier tipo de «política judicial». 62

El juego de contrapesos y equilibrios de estas dos cláusulas ve cierta luz con la novedad que supone la ley antes mencionada, RFRA Religious Freedom Restoration Act- de 199363 que fue consecuencia directa del giro de parámetros que supuso la sentencia Employment Division v. Smith64.

Smith era consejero de un centro dedicado a la rehabilitación de toxicómanos y alcohólicos dependientes. Una de las políticas del centro era la prohibición del consumo de drogas por sus trabajadores. Smith, indio nativo americano, fue despedido - junto con otro compañero- por consumir un alucinógeno leve llamado peyote, como parte de la celebración de un rito religioso. El Estado de Oregón denegó el derecho de subsidio al desempleo al demandante debido a que su despido fue procedente. Entonces, Smith denunció que el ejercicio de su derecho a la libertad religiosa había sido infringido. El Tribunal Supremo estableció que el Estado de Oregón es competente para prohibir el uso de peyote, como también lo es para dene-

61 Esta última fase se incorporó al balancing test en el caso Braunfeld v. Brown, 366 U.S. 599 (1961) y en Sherbert v. Verner, 374 U.S. 398 (1963).

62 Vid. R. PALOMINO, op. cit. pág. 41.

63 Para una aproximación detallada, vid. el trabajo conjunto sobre la Religious Freedom Restoration Act de R. F. DRINAN y J. I. HUFFMAN, "The Religious Freedom Restoration Act; A Legislative History", Journal of Law and Religion, vol. 10 (1993-1994) pp. 531-588.

64 Employment Division v. Smith, 494 U.S. 872 (1990). 
gar el subsidio de desempleo, sin que por ello se esté vulnerando la Free Exercise clause. El Juez Scalia, ponente de la sentencia, afirmó que el compelling state interest no puede ser aplicado a todos los supuestos en los que las creencias religiosas pueden verse vulneradas, puesto que en tal caso, el derecho de libertad religiosa sería un derecho ilimitado que no admitiria restricción alguna derivada de obligaciones civiles ${ }^{65}$. El TS no aplicó el balancing test en este caso estableciendo que no era necesario hacerlo en todos los casos en los que se vieran implicadas una norma estatal neutral y el derecho de libertad religiosa; al contrario, hay normas neutrales suficientemente importantes como para limitar el ejercicio de la libertad religiosa 66 .

En 1993, el TS ratifica los postulados de Smith en la sentencia que resuelve Church of the Lukumi Babalu Aye, Inc v. City of Hialeah ${ }^{67}$ aunque esta vez decidiendo a favor de la iglesia. La ciudad de Hialeah dictó una ordenanza municipal por la que se prohibía el sacrificio de animales en ceremonias religiosas, a sabiendas de que para la santería, y en especial, para la iglesia Lukumi Babalu Aye, era un rito esencial. La confesión religiosa alegó que la ordenanza vulneraba su libertad religiosa. En su defen-

\section{5 lbíd. 878-879.}

66 El caso Smith ha generado abundante lilteratura; cabe destacar: J. DELANEY, «Police Power Absolutism and Nullifying the Free Exercise Clause: A critique of Oregon v. Smith", Indiana Law Review núm. 25 (1991) pp. 71-137; J. D. GORDON, «Free Exercise on the Mountaintop", California Law Review núm. 79 (1991) pp. 91-130; D. LAYCOCK, «The Remnants of Free Exercise», Supreme Court Review núm. 1 (1990); M. C. MCCONNELL, "Free Exercise Revisionism and the Smith Decision" University of Chicago Law Review núm. 57 (1990) pp. 1109-1153; S. PEPPER, "Conflicting paradigms of Religious Freedom: Liberty versús Equality", Briangh Young University Law Review (1993) pp. 722; y T.J. CUNNINGHAM, "Considering Religion as a factor in Foster case in the aftermath of Employment Division, Department of Human Research v. Smith and Freedom Restoration Act", University of Richmond Law Review, núm. 28 (1994) pp. 53-117. Entre los artículos a favor del resultado de Smith, vid.:W. P. MARSHALL, «In Defense of Smith and Free Exercise Revisionism", University of Chicago Law Review, núm. 58 (1991) págs. 308 y ss.; S. SHERRY, "Lee v. Weisman: Paradox Redux" Supreme Court Review (1992) págs. 123 y ss. Para un compromiso entre Smith y sus críticos: C. E. EISBURGER y L. G. SAGER, "The Vulnerability of Conscience: The Constitutional Basis for Protecting Religious Conduct, University of Chicago Law Review núm. 61 (1994) pp. 1245-1315; y R. RAINS, "Can Religious Practice be given meaningful protection after Employment Division v. Smith?», University of Colorado Law Review, núm. 62 (1991) pp. 687-707. Por último, para una lista más extensa de los artículos sobre Smith, dirigirse aThe Religious Freedom Restoration Act: Hearing on S. 2669 Before the Committee on the Judiciary, 102d Cong. Segunda sesión 60-62 (1992) (Senate Hearings).

67 Church of the Lukumi Babalu Aye, Inc v. City of Hialeah, 113 S. Ct. 2217 (1993). 
sa, la ciudad de Hialeah alegó que con la ordenanza se buscaba impedir la crueldad contra los animales, evitar la comercialización y el consumo de los restos cárnicos, y prevenir problemas de sanidad e higiene. El Tribunal Supremo estimó que las ordenanzas no eran neutrales porque imponían selectivamente límites a las creencias religiosas de una determinada confesión, y por lo tanto afectaban directamente a la libertad religiosa de los creyentes de esta religión. Aunque el resultado de la sentencia deja a salvo el derecho a la libertad religiosa, no se llegó a este resultado por la aplicación de la doctrina del balancing test sino por la intencionalidad clara de esta ordenanza, la cual era restringir el ejercicio de la libertad religiosa. Con esta sentencia, el Tribunal estaba obviando las agresiones indirectas sobre el ejercicio de la libertad religiosa, y dejó abierta la posibilidad de que puedan promulgarse normas que son neutrales -aquéllas que cumplen el Lemon test- pero que perjudican de hecho, la libertad religiosa de algunos ciudadanos. Por lo tanto, reforzaba la jurisprudencia de Smith y limitaba la Free Exercise clause 68 .

Tras estos dos fallos del TS, el Congreso aprobó la Ley de Restauración para la Libertad Religiosa (RFRA), el 16 de noviembre de $1993^{69}$. Con ella se pretendió restaurar la teoría del balancing test y afirmar que los derechos individuales que emanan de la libertad religiosa son inviolables, a excepción de los casos en los que el Estado demuestre que la ley a aplicar es de tal envergadura que debe prevalecer sobre el libre ejercicio de la libertad religiosa, en cuyo caso la ley se aplicará utilizando los medios menos restrictivos ${ }^{70}$. Es decir, la RFRA transforma en legislación la previa doctrina jurisprudencial del compelling interest test y la doc-

\section{Vid. O. ANGÓN CELADOR, op. cit pág. 54.}

69 El Congreso promulgó la RFRA en virtud de la competencia que le atribuye la sección quinta de la decimocuarta enmienda. Como apuntamos, esta enmienda permite al Congreso promulgar leyes que garanticen el ejercicio de los derechos civiles de las diez primeras enmiendas y promulgar normas que garanticen la igualdad en el ejercicio de las libertades, señaladas en la decimocuarta contra la acción de los Estados, o bien sean normas de carácter exclusivamente preventivo para asegurar el ejercicio de estas libertades. El límite a esta facultad legislativa es no alterar el significado de los derechos protegidos por la decimocuarta enmienda ni suplantar las competencias de los Estados.

70 «Religious Freedom Restoration Act»: Sec. 2. Congressional Findings and Declaration of Purposes A FINDINGS: The Congress finds: (1) the framers of the Constitution, recognizing free exercise of religion as an unalienable right, secured its protection in the First Amendment to the Constitution; (2) laws «neutral" toward religion may burden religious exercise as surely as laws intended to interfere with religious exercise; (3) governments should not substantially burden religious exercise without compelling justifications; (4) in Employment Division v. Smith, 494 U.S. 872 (1990) the 
trina sobre las exenciones a la ley por motivos religiosos; de ahí su autodenominación como "ley de restauración». Para el Gobierno federal, la RFRA significaba dos cosas: por un lado, es una norma de interpretación para futuras labores legislativas; y por otro, tiene el cometido de supervisar la labor de las agencias federales 71 . Fue promovida por las más variadas coaliciones y grupos religiosos, incluyendo tanto a cristianos, judíos, musulmanes, sikhs, humanistas como a organizaciones civiles liberales ${ }^{72}$.

Supreme Court virtually eliminated the requirement that the government justify burdens on religious exercise imposed by laws neutral toward religion; and (5) the compelling interest test as set forth in prior Federal court rulings is a workable test for striking sensible balances between religious liberty and competing prior governmental interests. B/ PURPOSES:The purpose of this Act are: (1) to restore the compelling interest test as set forth in Sherbert v. Verner, 374 U.S. 398 (1963) and Wisconsin v. Yoder, 406 U.S. 205 (1972) and to guarantee its application in all cases where free exercise of religion is substantially burdened; and (2) to provide a claim or defence to persons whose religious exercise is substantially burdened by government. Sec. 3 Free exercise of religion protected (a) In general: Government shall not substantially burden a person's exercise of religion even if the burden results from a rule of general applicability, except as provided in subsection (b) Exception: Government may substantially burden a person's exercise of religion only if it determines that application of the burden to the person: (1) is in furtherance of a compelling governmental interest; and (2) is the least restrictive means of furthering that compelling governmental interest.

71 Vid. D. LAYCOCK y O. S. THOMAS, «Interpreting the Religious Freedom Restoration Act», Texas Law Review, núm. 73 (1994) pp. 209-243 en pág. 210.

72 La Coalición para el Libre Ejercicio de la Libertad Religiosa incluyó una amplia tipología de grupos religiosos que nos sirve de botón de muestra del pluralismo religioso estadounidense: Agudath Israel of America; American Associations of Christian Schools; American Civil Liberties Union; American Conference of Religious Movements; American Humanist Association; American Jewish Committee; American Jewish Congress; American Muslim Council; American for Democratic Action; American for Religious Liberty; Americans United for Separation of Church and State; Anti-Defamation League; Association of Christian Schools International; Association on American Indian Affairs; Baptist joint Committee on Public Affairs; Central Conference of American Rabbis; Christian Church (Disciples of Christ); Christian College Coalition; Christian Legal Society; Christian Life Commission of Southern Baptist Convention; Christian Science Committee on Publication; Church of the Brethren; Church of Jesus Christ of Latter-day Saints; Church of Scientology International; Coalitions for America; Concerned Women for America; council of Jewish Federations; Council on Religious Freedom; Episcopal Church; Evangelical Lutheran Church in America; First Liberty Institute; Friends Committee on National Legislation; General Conference of Seventh-day Adventist; Guru Gobind Singh Foundation; Hadassah, The Women's Zionist Organization of America, Inc.; Home School Legal Defence Association; House of Bishops of the Episcopal Church; International Institute for Religious Freedom; Japanese American Citizens League; Jesuit Social Ministries, National Office; Justice Fellowship; Mennonite Central Committee U.S.; NA'AMAT USA; National Association of Evangelicals; National Council of 
No obstante, muy poco tiempo después, con la sentencia del caso City of Boerne v. Flores, Archbishop of San Antonio 73 , elTS declaró inconstitucional la RFRA. El caso resolvía la disputa entre una iglesia católica y la ciudad de Boerne en el Estado de Texas. La iglesia pretendía ampliar y remodelar el edificio de su iglesia para poder atender debidamente la reciente demanda del culto, pero su solicitud al ayuntamiento fue desestimada, alegando que el edificio aparecía en el inventario del patrimonio histórico artístico de la ciudad. El obispo de San Antonio denunció la inconstitucionalidad de la norma urbanística. El Tribunal del Distrito que resolvió el caso en primera instancia consideró la RFRA inconstitucional. En apelación, el Tribunal del Quinto Circuito revocó la sentencia y fallo a favor de la constitucionalidad. Finalmente, el TS desestimó la sentencia del Tribunal del Circuito e interpretó que la RFRA era inconstitucional74.

Churches; National Council of Jewish Women, National Federation of Temple Sisterhoods; National Islamic Prison Foundation; National Jewish Commission on Law and Public Affairs; National Jewish Community Relations Advisory Council; National Sikh Centre; Native American Church of North America; North American Council for Muslim Women; People for the American Church of North American; North American Council of Muslim Women; Presbyterian Church (USA); Rabbinical Council of America; Traditional Values Coalition; Union of American Hebrew Congregations; Union of Orthodox Jewish Congregations of America; Unitarian Universalist Association of Congregations; United Church of Christ; United Methodist Church; United Synagogue of Conservative Judaism. Por último, the American Bar Association no se unió a la coalición pero ratificó la ley. lbid. pág. 236.

73 Flores v. City of Boerne, 117 S.Ct. 2157 (1997).

74 La Ley para Restaurar la Libertad Religiosa fue declarada inconstitucional basándose en tres motivos: 1. Supone una intrusión seria del Congreso federal en las competencias legislativas de los Estados porque "prescribe a los Estados lo que la decimocuarta enmienda, en sí misma, no prohibe" $y$, además, modifica el alcance y contenido del derecho constitucional a la libertad religiosa; 2 . Su ámbito de aplicación ha sido una norma neutral que tiene como sujeto pasivo el conjunto de los ciudadanos de dicha ciudad, creyentes o no creyentes. Por lo tanto, no tiene una función preventiva como garantía a la libertad religiosa. Además, con la RFRA se ofrece una protección desmedida y desproporcional al derecho de libertad religiosa; 3. El Congreso federal se ha excedido con la promulgación de la RFRA puesto que esta ley tiene como objeto guiar la decisiones de los casos y controversias judiciales, las cuales sólo deben obedecer a la regla del precedente. Por lo tanto, se está vulnerando el principio de separación de poderes. Sobre la separación de poderes y la RFRA, vid. M. STUART, «The Religious Freedom Restoration Act of 1993: Restoring Religious Freedom After the Destruction of the Free Exercise Clause», University of Dayton Law Review, núm. 20 (1994) pp. 383-422 en pág. 398. 
Merece la pena destacar los votos particulares de los jueces Stevens y O'Connor. Para la última, la RFRA es constitucional porque la libertad religiosa no puede sufrir menoscabo con normas de carácter general, puesto que tanto la libertad religiosa como la de expresión gozan de una protección especial pues ambas forman parte del contenido esencial del derecho de la libertad de pensamiento y conciencia 75 . El Juez Stevens, por su parte, era partidario de la inconstitucionalidad de la RFRA puesto que la legislación no puede conceder un trato preferencial a la religión con respecto al resto de creencias ideológicas. Si el edificio hubiese pertenecido a un ateo o fuera un museo hubiesen estado vinculados por las normas urbanísticas sin posibilidad de excepción, de modo que RFRA ofrece prerrogativas a las confesiones religiosas que no disfrutan el resto de no creyentes; por lo tanto, se está violando la cláusula de no-establecimiento.

El caso sobre la Ciudad de Boerne generó una fuerte polémica en la judicatura 76 y en la doctrina77. Declarada la inconstitucionalidad de la RFRA, el precedente directo e inmediato volvía a ser la sentencia Smith que

\section{Vid. O. CELADOR, cit pág. 57.}

76 Los tribunales inferiores federales se han dividido sobre la cuestión de la constitucionalidad o no de la RFRA: Grand Jury Empanelling of Special Grand Jury, 171 F. 3d 836 (3d Cir. 1999) "Courts have since disagreed over whether RFRA is constitutional as applied to the federal government ... Here ... we need not decide whether any part of RFRA survives (City of Boerne v. Flores), because we conclude that the federal government's action in this case would survive strict scrutiny even under the rigorous RFRA standard»; Sutton v. Providence St. Joseph Medical Center, 192 F. 3d 826, 830 (9th Cir. 1999): «Most courts that have considered the issue have concluded that the Supreme Court invalidated RFRA only as applied to state and local lawn; United States v. Muhammad, 165 F. 3d 327, 336-337 (5th Cir. 1999): «courts disagree as to the constitutionality of RFRA as applied to federal governmental action". Vid. los casos recogidos en E. J.W. BLATNIK, "No RFRA Allowed:The Status of Religious Freedom Restoration Act's Federal Application in the Wake of City of Boerne v. Flores», Columbia Law Review, núm. 98 (1998) pp. 1410-1412. Sobre la no aplicación de la inconstitucionalidad de la RFRA declarada en Boerne a la legislación federal, vid: E. GRESSMAN, "The Necessary and Proper Downfall of RFRA" en Nexus Journal of Opinion núm. 2 (1997) pp. 73-98, "Boerne had no occasion to assess RFRA's constitutionality with respect to its application to federal statutes and regulations..." pág. 81 .

77 Vid: D. O. CONKLE, "Congressional Alternatives in the Wake of City of Boerne v. Flores: The Limited Role of Congress in Protecting Religious Freedom From State and Local Infringement» University of Arkansas Little Rock Law Journal, núm. 20 (1998) pp. 633-667; K. GREENAWALT, wWhy now is not the Constitutional amendment: The limited reach of city of Boerne Flores", Williams and Mary Law Review, vol. 39 (1998) pp. 689678; y D. LAYCOCK, "Conceptual gulfs in City of Boerne v. Flores", Williams and Mary Law Review vol. 39 (1998) pp. 679-715;T.W. BEINERS, "Searching for the structural vision of City of Boerne v. Flores: the new Constitutional Architecturen, Hasting Constitutional Law Quarterly, vol. 26 (1999) pp. 789-852; K. S. KANDA, "Validity and application of the religious freedom restoration act in the tenth Circuit after City of Boerne v. Flores", 
había cerrado, por así decir, un ciclo favorable a la libertad religiosa. En tal caso, el TS indicó que si una conducta es criminalmente sancionada no le será aplicable el compelling state interest test. En cuanto a las posibles exenciones a las normas jurídicas, por otro lado, se habrá de acudir al poder legislativo que goza de prerrogativas para disponer de las mismas 78 .

\section{Una revisión de la cláusula de no establecimiento: Mitchell v. Helms y Santa Fe v. Doe}

\subsection{El acomodo de las creencias religiosas en la cláusula de no establecimiento,}

Según el principio de separación Iglesia-Estado y de la cláusula de no establecimiento, el Estado no debe ayudar, favorecer o promover una religión determinada79. Con las exenciones a las leyes de carácter general históricamente se ha buscado el acomodo de aquellas personas cuyas creencias divergen de las mayoritarias; en tales casos, el Estado ha garantizado el libre ejercicio de la religión aunque indirectamente, con las exenciones, parte de la doctrina haya apuntado un alejamiento del principio de neutralidad, formalmente entendido 80 . La orientación que se ha ido

Denver University Law Review, vol. 79 (2002) pp. 295-330; R. COLKER, «The Supreme Court's historical errors in City of Boerne v. Flores», Boston College Law Review, vol. 43 (2002) pp. 783-818.

78 R. PALOMINO, op. cit. pág. 46. El resultado fue que, con Smith, la libertad religiosa queda seriamente dañada y todas las posibilidades de acomodo en razón del libre ejercicio de la religión pasan a depender de la dinámica del proceso político que tendrán que responder ante todo los conflictos, vid. M. MCCONNELL, «Accommodation of Religion», cit. pág. 711.

79 Uno de los trabajos más completos sobre la Establishment Clause es el de D. O. CONKLE, "Toward a General Theory of the Establishment Clause» en Northwerstern University Law Review, núm. 82 (1988) pp. 1115-1177. La cláusula de no establecimiento nace en la teoría de la separación de Jefferson y en su famosa metáfora del «muro de separación" entre Iglesia y Estado. El Juez Black lo articula en Everson v. Board of Education (330 U.S. 1 1947), de la siguiente manera: "First Amendment means at least this: Neither state nor the Federal Government can set up a church. Neither can pass laws which aid one religion, aid all religions or prefer one religion over another", en 15. Para la historia de la Establishment Clause y el test Lemon, vid. S. A. SEIDMAN, "County of Allenghency v. American Civil Liberties Union: Embracing the endorsement test", Journal of Law and Religion, núm. 9 (1991) pp. 211-241.

80 Vid. el estudio del principio de neutralidad en M. PAULSEN, «Religious Equality and the Constitution: an Equal protection Approach to Establishment Clause Adjudication" en Notre Dame Law Review núm. 61 (1986) pp. 311-360. 
abriendo paso, impulsada por los grupos minoritarios, es una relectura de los postulados neutrales desde el concepto de "libre ejercicio». Así, un buen número de comentaristas norteamericanos han sugerido un concepto de «libre ejercicio" con postulados neutrales que "permita que el Estado pueda "cooperar" con la religión en orden y estructurar un planteamiento secular que, de algún modo, apoye a los individuos a defender sus intereses religiosos" 81 .

Un programa gubernamental que favorezca deliberadamente determinados intereses religiosos, o una exención a la ley que exima a los ciudadanos del cumplimiento de una ley, violará directamente la cláusula de no establecimiento si cualquiera de ellos - el programa gubernamental o la exención - es una grave amenaza a la libertad religiosa o son, en sí mismos, discriminatorios 82 . Por razones históricas y distintas motivaciones personales, los miembros del Tribunal han excusado de las leyes de carácter general a miembros de confesiones minoritarias 83 aunque se han mostrado más reticentes a la hora de solucionar los problemas que conlleva el "acomodo" 84 de estas creencias. El acomodo de las prácticas religiosas no es automáticamente inconstitucional pero está sometido a un control fundamentalmente judicial. En Board of Education of Kiryas Joel Village School District v. Grumet ${ }^{85}$, el Tribunal resaltó las dificultades que encuentran los grupos minoritarios, tanto en el procedimiento administrativo, judicial como legislativo, para conseguir los mismos beneficios que obtiene la mayoría en todos estos procedimientos 86 . Si el acomodo

81 G. MORÁN, «La protección jurídica...» cit. pág. 63.

82 Este es principio conocido como uIntentional Advantage Principlen: "Government programs that deliberately favour religious interest or government actions that relieve individuals because of their religious beliefs from the burdens of generally applicable regulations should be held to violate the Establishment Clause only if programs or actions pose a significant threat to religious liberty or if they are discriminatory", J. CHOPER, Securing Religious Liberty, Principles for Judicial Interpretation of Religion Clauses, University of Chicago Press, Chicago (1995) pág. 97.

83 Lo han hecho los simpatizantes de la corriente más liberal como el Juez Brennan o los conservadores como O'Connor o Scalia.

84 J. CHOPER, Securing Religious..., cit. pág. 100.

85 Board of Education of Kiryas Joel Village School District v. Grumet, 114 S. Ct. 2481 (1994).

86 «The real risk that legislative accommodations for religion will turn more on political favouritism and influence than on judgments of constitutional entitlement or acute religious need", en I. C. LUPU, "Reconstructing the Establishment Clause:The Case against Discretionary Accommodation of Religion" en University of Paul Law Review, núm. 140 (1994) pág. 602. 
viene de la mano del legislativo pueden crearse verdaderas diferencias de protección de la libertad religiosa entre los Estados ${ }^{87}$. En algunos de ellos, los demandantes han buscado las exenciones en instancias judiciales porque no las han encontrado en el proceso legislativo estatal, mientras que en otros Estados, el mismo caso venía recogido como exenciones particulares en disposiciones legislativas ${ }^{88}$. En Kiryas Joel School, el TS confirmó un principio relativamente extendido: el acomodo se extenderá no sólo a los grupos religiosos sino a cualquier grupo que se encuentre en una situación y un contexto parecido al del grupo religioso. La sentencia delTS invalida la creación de un distrito especial escolar para estudiantes minusválidos de la comunidad de los judios ortodoxos hasídicos en el estado de Nueva York. Sostuvo que el acomodo era inviable porque "confiere un trato especial a una comunidad religiosa sin asegurarse que otro grupo en una situación similar en un futuro reciba el mismo tratamiento»89; por lo tanto, el Tribunal concluyó que "cualesquiera que sean los límites de un razonable acomodo legislativo, un distrito especial viola el principio de neutralidad $" 90$.

Desde el punto de vista de la neutralidad formal, es posible interpretar las exenciones como "inmunidades" que benefician a una religión sobre otra. Sin embargo, esta es una de las consecuencias del mismo efecto que tienen las exenciones bajo la cláusula de libre ejercicio de la Primera Enmienda. Rechazar las exenciones a la ley implicaría rechazar el acomodo

87 Las consecuencias son: 1. No existirá un patrón común para el tratamiento especial por motivos religiosos; 2 . Pueden darse privilegios específicos para una religión en estados concretos, según la mayoría, y 3 . Se crea el riesgo serio de omisión de las exenciones a las religiones que no gocen del favor mayoritario, Ibíd. 605-606.

88 Uno de los casos más conocidos es el uso del peyote: en Employment Division v. Smith se denegó su uso en Oregón mientras que en otros veintitrés estados, y el propio Gobierno federal, habian recogido estas exenciones para su uso en sus leyes penales. Junto a Wisconsin v. Yoder, otros cuatro estados reconocian en sus leyes algún tipo de exención a la asistencia a la escuela a los estudiantes Amish. En cuanto a las leyes del domingo, veinte de los treinta y cuatro estados con leyes sobre la regulación del descanso dominical habian concedido las exenciones a aquellos comerciantes que abrían los domingos. Por último, después de que el Tribunal denegase la excepción a un judio ortodoxo al reglamento sobre la vestimenta para poder llevar el yarmulke con el uniforme militar, el Congreso pasó una ley autorizándolo: Public Law 100-180, sec. 508, 100th Cong. 1st sess (1987).

89 Board of Education of Kiryas Joel Village School District v. Grumet, 2493.

90 Ibíd. 2493-2494. 
de cualquier práctica religiosa91 e iría contra el "espíritu» de los fundadores $^{92}$. A diferencia de lo que sostienen aquellos partidarios de la neutralidad en sentido estricto, hay autores que opinan que el acomodo es el resultado del principio de libertad religiosa de la cláusula de libre ejercicio y es, por definición, un coste que debe asumir el Estado puesto que es constitucionalmente admisible 93 . La dificultad surge a la hora de determinar en qué casos una exención por motivos religiosos favorece o beneficia a una religión ${ }^{94} \mathrm{y}$, por lo tanto, puede verse violada la cláusula de no establecimiento 95 . En ocasiones, aunque el acomodo de algunas prácticas religiosas no menoscabe el ejercicio del derecho de libertad religiosa de otros directamente, puede entenderse como un favoritismo hacia unas creencias determinadas si con el acomodo el Gobierno coacciona las creencias de terceros, incita a participar de unas creencias a las que el sujeto no se hubiese adherido de otro modo, o bien lo obliga a sostener económicamente unas creencias distintas a las propias ${ }^{96}$.

91 Hay numerosos artículos que discuten el acomodo de las prácticas religiosas. Entre los más interesantes están: M.W. MCCONNELL, "Accommodation of Religion" en George Washington Law Review núm. 60 (1992) pp. 685-744; M. TUSHNET, "Of Church and State and the Supreme Court: Kurland Revisited, Supreme Court Review (1985) pp. 373 y ss. $y$ sThe Emerging Principle of accommodation of religion (dubitante)", Georgetown Law Journal núm. 76 (1988) pp. 1691-1711; T. L. HALL, "Religion, Equality and Difference", Temp. Law. Review núm. 65 (1992) pp. 1-36 y J. E. NECHTERLEIN, »The Free Exercise boundaries of permissible accommodation under the Establishment Clause" en Yale Law Journal, núm. 99 (1990) pp. 1127-1147.

92 "Accommodation principle fits albeit not entirely comfortably into the complex and somewhat inconsistent structure of government and political theory that the framers had in mind" en M.TUSHNET, Ibíd. (1988) cit. pág 1699.

93 Vid. al respecto: $M$. TUSHNET, «Reflections on the Role of Purpose in the Jurisprudence of the Religion Clauses» en William and Mary Law Review (1986) pp. 997 y ss; J. N. MOORE, «The Supreme Court and the Relationship between the 'Establishment' and 'Free Exercise' Clauses en Texas Law Review, núm. 42 (1963) pp. 142-199.

94 Según K. GREENAWALT: "To call the purpose 'secular' is to obscure the reality that the purpose to accommodate religion is often not very different from the purpose to promote religion", "Religion as a Concept in Constitutional Law" en California Law Review, núm. 72 (1984) pp. 753-806 en pág. 797.

95 En ocasiones, la exención individual no es suficiente para garantizar la libertad religiosa. También se ha adoptado el enfoque de la Establishment Clause desde la 'acción popular' y desde él se han analizado la jurisprudencia de la Establishment Clause, S. J. WARD, «Reconceptualizing Establishment Clause cases as Free Exercise Class Actions» en Yale Law Journal núm. 98 (1989) pp. 1739-1761.

96 Son los casos de los belenes en los espacios públicos como en los Ayuntamientos. En Elewski v. City of Syracuse, 123 F. 3d 51 (2d Cir. 1997), el Tribunal del Segundo Circuito sostuvo que estas exposiciones no violaban la Establishment Clause de la Primera Enmienda; puesto que para un observador era una tradición razonable. 
Estas dificultades han encontrado una posible solución en una reciente sentencia del Tribunal federal del Octavo Circuito, Children's Healthcare is a legal duty v. Min de Parle, (CHILD II)97, en el que se sostuvo la inclusión de los Christian Science en los programas gubernamentales de Ayuda Médica si reunían los criterios establecidos para cualquier institución, secular o religiosa. De este modo, este grupo religioso se benefició de ventajas fiscales sin que por esto significase el fomento y promoción de la institución religiosa. El Tribunal adopta otro enfoque sobre el acomodo: en primer lugar, se estudiará principalmente si el acomodo elimina los obstáculos para el ejercicio de la libertad religiosa y, en segundo lugar, si crea incentivos para la práctica de una determinada religión. Las exenciones que conceden las leyes se analizarán a la luz de la promoción o inhibición de la libertad religiosa y el acomodo será admisible cuando permita el libre ejercicio de la libertad religiosa sin incentivar su práctica.

A mi entender, esta aproximación a las dos cláusulas permite maximizar el principio de libertad religiosa, si bien no está exenta de críticas desde el punto de vista de la cláusula de no establecimiento. Estas críticas pueden salvarse dependiendo de la interpretación que se haga de esta última cláusula. Fundamentalmente, existen dos aproximaciones a esta cláusula: el enfoque radical y el moderado.

Para los partidarios del enfoque radical, el Gobierno no puede llevar a cabo ninguna acción que presuponga el avance o el apoyo a un credo religioso o la preferencia por el sentimiento religioso sobre lo no religioso. Conforme al mismo, la cláusula de no establecimiento sería también infringida por la expresión "In God WeTrust» en la moneda americana o la invocación al inicio de las sesiones en el Tribunal Supremo "God save the United States and this Honorable Court». Este enfoque ha ido perdiendo adeptos en la doctrina americana ${ }^{98}$ y el debate se ha trasladado a los planteamientos $y$ al alcance de lo que se conoce como el enfoque moderado.

Esta fue la postura de la Jueza O'Connor. Por el contrario, el Juez Stevens sostuvo que esta "razonabilidad" debía cuestionarse puesto que en una sociedad multicultural, el universo de "personas razonables" está también compuesto por los grupos minoritarios. Para un análisis de este caso, vid. el trabajo de B. J. SACHS, "Who Reasonableness counts?, Elewski v. City of Syracuse», 123 F. 3d. 51 (2d Cir. 1997) en Yale Law Journal, núm. 107 (1998) pp. 1523-1532.

97 Children's Healthcare is a legal duty v. Min de Parle, (CHILD II), 212 F. 3d 1084 (8th Cir. 2000), denegado el certiorary, 121 S. Ct. 1483 (2001).

98 Vid. el artículo al respecto de C. H. ESBECK, "A Restatement of the Supreme Court's Law of Religious Freedom: Coherence, Conflict or Chaos?" en Notre Dame Law 
Según el mismo, está fuera de duda que la Constitución contiene una garantía mínima, por la cual, el Gobierno no coaccionará a nadie a apoyar o participar de unas creencias religiosas 99 . Además de esta garantía, el enfoque moderado impide que el Estado apoye unas determinadas creencias, con la salvedad de las menciones en las monedas, en la Constitución o en los tribunales. Las exenciones concedidas al amparo de la cláusula de no establecimiento estarían justificadas como parte de la historia jurisprudencial estadounidense ${ }^{100}$, siempre y cuando, se demuestre que tenían naturaleza religiosa y eran necesarias. La versión moderada de la cláusula de no establecimiento, a diferencia de la versión radical, permite al Gobierno privilegiar mediante las exenciones oportunas, las prácticas religiosas, sean del tipo que sean. Esto quiere decir -como apuntan Laycock 101 y Gedicks ${ }^{102}$ - que el Gobierno no debe distinguir entre actos de la conciencia entendidos desde un punto de vista religioso y actos de conciencia expresados en términos no religiosos; entre creencias teísticas y creencias no teísticas 103 .

Review núm. 70, (1995) pp. 581-615. También merecen destacarse las palabras del Juez Scalia en Texas Monthly, Inc. v. Bullock, 489 U.S. 1 (1989): "(...) the bold but unsupportable assertion (given such realities as the text of the Declaration of Independence, the nationalThanksgiving Day proclaimed by every President since Lincoln, the inscription on our coins, the worlds or our Pledge of Allegiance, the invocation with which sessions of our Court are opened...) that government may not convey a message of endorsement of religion", en 29-30.

99 En School District v. Schempp, 374 U.S. 203 (1963), el Tribunal señalaba que el elemento de la coacción no es un elemento esencial para que hubiera violación de la Establishment: " It is necessary in a free exercise case for one to show the coercive effect of the enactment as it operates against him in the practice of his religion. The distinction between the two clauses is apparent (...) a violation of the Free Exercise Clause is predicated on coercion while the Establishment Clause violation need not to be so attended", en 223. Vid. también el artículo a favor de este plantemiento de S. G. GEY, “Religious Coercion and the Establishment Clause", University of Illinois Law Review, (1994) pp. 463-492.

$100 "(. .$.$) is part of our constitutional law, it is not surprising that the Supreme$ Court rejects - every sitting Justice except Justice STEVENS rejects - the position that government may never exempt religious practice as such", School District v. Schempp, 177 F. Sup. 398 (E.D. Pq. 1959).

101 D. LAYCOCK, "Religious Liberty as Liberty", Journal Contemporary Legal Issues, núm. 7 (1996) pp. 313-345.

102 F. M. GEDICKS, "An Unfirm Foundation: The Regrettable Indefensibility of Religious Exemptions", University of Arkansas Little Rock Law Journal, (1998) pp. 55-82.

103 En la conclusión del trabajo de Laycock apunta: “The Law should protect nontheists' deeply held conscientious objection to compliance with civil law to the same extent that it protects the theistically motivated conscientious objection of traditional believers. United States v. Seeger and Welsh v. United States were rightly decided; they implement policies at the core of religious liberty. The law cannot protect the pursuit of 
A continuación, se analizará la cláusula de no establecimiento en el área educativa donde se presentan mayores problemas para el acomodo. Las cuestiones de las ayudas financieras, directas o indirectas, a organizaciones religiosas o a escuelas religiosas primarias o secundarias 104 ; la prohibición a las escuelas religiosas de adherirse a los programas de subsidio gubernamentales o la constitucionalidad de que el Gobierno las incluya en programas públicos seculares; y el acomodo de los mensajes y prácticas religiosas en los recintos educativos han sido objeto de revisión y estudio en dos sentencias emblemáticas del TS que han cambiado el curso de la relación entre las dos cláusulas de la Primera Enmienda norteamericana.

\subsection{Cuando la neutralidad es enemiga de la separación}

4.2.1. Las consecuencias del principio de neutralidad: Mitchell $v$. Helms ${ }^{105}$

En Mitchell, un grupo de padres denuncian la constitucionalidad del Capítulo 2 de la Education Consolidation and Improvement Act de 1981 porque violaba directamente la cláusula de no establecimiento. Mediante este programa, el Congreso distribuia ayudas económicas a las escuelas para la adquisición de materiales escolares e informáticos para el colegio. Estas ayudas federales se enviaban a través de agencias educativas a escuelas primarias, secundarias, bien públicas o bien privadas. Todos los materiales adquiridos, tanto de equipo como los de servicio, debían de ser "seculares, neutrales y no ideológicos" 106. Los demandantes alegan que el $30 \%$ de las ayudas para la Parroquia Jefferson se destinaban a escuelas

all prudence of political decisions. Unlike religious disagreements, political disagreements are committed to the political process ... What the law can do is protect those moral obligations of nontheists that are functionally equivalent", D. LAYCOCK, "Religious Liberty...", cit. pág. 331.

104 En efecto estos casos son los que más agitación ha levantado y en los que el Tribunal Surpremo no ha sido capaz de encontrar una opinión coherente: "There is a virtual consensus among commentators that the Supreme Court's opinions about government aid to religious affiliated schools -in particular, its decisions about aid to religiously affiliated primary and secondary schools- are an unholy mess. It is difficult to discern a non artibitrary distinction between the situations in which the Court has invalidated government aid to religiously affiliated primary or secondary schools and the situations in which it has declined to do so". J. CHOPER, Securing Religious..., pp. 174-175.

105 Mitchell v. Helms, 120 S. Ct. 2530 (2000).

10620 U.S.C., 7372 (a) (1) (2000). 
privadas católicas $y$, por lo tanto, tales ayudas podrían fácilmente adquirir un uso religioso; en consecuencia, el Capítulo 2 de dicha ley podría incurrir en ayuda y promoción de una religión.

EITS falló a favor de la constitucionalidad del Capítulo 2 a falta de pruebas que confirmasen un posible adoctrinamiento religioso o una preferencia por los beneficiaros por motivos religiosos. El fallo estaba formado por el voto plural mayoritario de los Jueces Rehnquist, Scalia y Kennedy y los votos concurrentes pero separados de los Jueces $O^{\prime}$ Connor y Bryer. El Juez Souter suscribió un voto particular discrepante a la mayoría al que se sumaron los Jueces Stevens y Ginsburg.

\subsubsection{Análisis de los fundamentos jurídicos}

Es necesario detenerse, respectivamente, en los razonamientos juridicos de los distintos jueces ponentes de la mayoría, en el voto particular concurrente $y$ en el particular discrepante con la finalidad de esclarecer el contenido de la cláusula de no establecimiento 107.

Por lo que respecta al voto plural de la mayoría, elTS confirma explícitamente el caso Agostini como el precedente más inmediato a seguir. En Agostini v. Felton ${ }^{108}$ se había admitido el derecho de los alumnos a bene-

107 Los fundamentos jurídicos del caso Mitchell ha sido estudiado ampliamente por la doctrina. Entre los trabajos más relevantes: A. M. BRABENDER, "Constitutional Law: Establishment Clause: the movement towards neutrality as the single criteria for determining the constitutionality of school aid under the Establishment Clause Mitchell v. Helms, 120 S. Ct. 2530 (2000)», North Dakota Law Review, vol. 77, (2001) pp. 97-121; D. H. DAVIS, "Mitchell v. Helms and the modern cultural assault on the separation of church and state", Boston College Law Review, vol. 43 (2002) pp. 1035-1070; I. LUPU, "Government messages and government money: Santa Fe, Mitchell v. Helms, and the arc of the Establishment Clause", William and Mary Law Review, vol. 42 (2001) pp. $771-$ 822; P. A. SWIFT, «Mitchell v. Helms: Does Government aid to religious schools violate the first Amendment? An extensive analysis of the decision and its repercussions?", Catholic Lawyer, vol. 41 (2001) pp. 169-186; S. K. GREEN, «The Constitutionality of vouchers after Mitchell v. Helms", New York University Survey of American Law, vol. 57 (2000), pp. 57-73; y J. F. MEAD y J. K. UNDERWOOD, «Lemon Distilled with fours votes for vouchers: An examination of Mitchell v. Helms and its implications", West's Education Law Reporter, vol, 149 (2001), pp. 639-658.

108 Agostini v. Felton, 571, U.S. (1997). Aunque tradicionalmente la inclusión de las escuelas religiosas en los planes de "bonos" ha estado permitida constitucionalmente, la polémica se aviva con el caso Rosenberger $v$. Rector and visitors of the University of Virginia, 515 U.S. 819 (1995). En la sentencia que decidió el caso, el Tribunal estimó que los grupos religiosos privados accederán a la ayuda gubernamental en igualdad de condiciones como cualquier otro grupo. Como señala J. R. Polo, ula idea de 
ficiarse de ciertas prestaciones educativas de carácter público, con independencia del tipo escuela a la que asistan. Con esta sentencia, elTS abandonaba definitivamente el Lemon test, a favor de un criterio menos riguroso que «tiende a declarar que la actuación estatal no conculca la cláusula de no establecimiento, a menos que produzca una promoción pública de la religión o una coacción al individuo porque participe en una actividad religiosa" 109. Para ello, elTS exponía tres criterios indicativos para analizar cuándo la actuación estatal desencadena una promoción de la religión o una disminución de la libertad religiosa. Estos criterios se desarrollan mediante un test de tres aspectos: 1) el Tribunal analizará si del programa del Gobierno resulta un adoctrinamiento; 2) Además, estudiará si el programa selecciona a sus beneficiarios por criterios religiosos; 3) y finalmente, el Tribunal determinará si se crea un excesivo entanglement entre la Iglesia y el Estado..

Para lo que aquí nos interesa, Mitchell selecciona dos de los criterios del razonamiento de Agostini. Mediante el primero, se analiza si el Capítulo 2 promociona la religión en el momento de la elección de los beneficiaros de las ayudas. EITS estima que las ayudas a Jefferson Parish se destinan "mediante criterios neutrales y seculares y ni ayuda ni perjudica a la religión (...) si las ayudas a los colegios están disponibles neutralmente y, antes de beneficiar a cualquier colegio religioso, pasan por numerosos ciudadanos particulares que deciden libremente dirigirlas a los colegios que estimen oportunos, el Gobierno no está sosteniendo a ninguno de ellos (...) por lo tanto, todo el dinero que reciba un colegio religioso será el resulta-

constitucionalidad de la asistencia incidental a la religión cuando esta sea consecuencia de una medida estatal formalmente neutral es ratificada por el Tribunal» en J. R POLO, La libertad de enseñanza en el derecho norteamericano, Servicio de Publicaciones de la Complutense, Madrid (1999) pág. 164. El fundamento jurídico en Rosenberger difiere de los casos parecidos que se habían decidido antes. En este caso, el fundamento se centra en la libertad de expresión puesto que la exclusión de potenciales beneficiarios por motivos religiosos viola la Cláusula del Free Speech. Con esta sentencia y a través de la Primera Enmienda se crea el derecho afirmativo a la igualdad de condiciones en el acceso a los fondos públicos. También En Zobrest v. Catalina Foothills Sch. Dist, 113 S.Ct. 2462 (1993) se estimó que un programa que solicitaba un intérprete para sordos a un chico que atendía una escuela religiosa no violaba la Establishment Clause; en Witters v. Washington Department of Service for the Blind, 474 U. S. 481 (1986), el Tribunal consideró que la ayuda financiera a un estudiante que se preparaba para ser ministro en un college religioso no contravenía la Establishment Clause; y en Mueller v. Allen 463 U.S. 388 (1983) se estimó que una ley de Minnesota que permitía desgravar los gastos de mantenimiento de los hijos a una escuela religiosa no era inconstitucional.

109 Vid. J. R. POLO, op. cit. pág. 166. 
do de la elección individual de los ciudadanos» ${ }^{110 . ~ A ~ t r a v e ́ s ~ d e l ~ s e g u n d o ~}$ criterio del análisis de Agostini, el TS considera que el programa de la Jefferson Parish School no promociona el adoctrinamiento religioso. Dado que las ayudas se reparten igualmente tanto para colegios de corte religioso como para aquellos seculares, el TS estima que no se está creando un incentivo para la asistencia a los religiosos. Además, si las ayudas que no tienen un contenido religioso están disponibles para todos colegios y su atribución se realiza mediante procedimientos previamente establecidos, el uso que se haga de esas ayudas no es competencia del Gobierno. Por lo tanto, si de este uso deriva un adoctrinamiento, no será competencia de los tribunales entrar a su valoración constitucional. La pluralidad de la mayoría centró el estudio de la violación de la cláusula de no establecimiento en el contenido neutral de las ayudas disponibles. De este modo, el TS no sólo no se aparta de Agostini sino que además reduce el test de constitucionalidad de las ayudas públicas a los colegios a la comprobación de la naturaleza neutral de las mismas.

Como he señalado anteriormente, la Juez $\mathrm{O}^{\prime}$ Connor concurre en el fallo de la sentencia pero divergiendo de los argumentos recién expuestos ${ }^{111}$. En su opinión, no debe reducirse el test de constitucionalidad a una única dimensión de la neutralidad. A diferencia de la mayoría, estima que es intolerable el sistema de destino de los fondos previsto en el Capítulo 2: sólo es posible sostener la constitucionalidad de las ayudas del Gobierno empleadas para fines religiosos cuando las mismas se conceden directamente a los ciudadanos y son ellos los que les eligen el destino. Por el contrario, en el caso presente, las ayudas gubernamentales se conceden siguiendo la asistencia y participación escolar, resultando el tratamiento análogo al que daría el Gobierno si concediera subvenciones a las iglesias en virtud del número de feligreses ${ }^{112}$. Es decir, significaría un apoyo explícito a una institución religiosa, y, por tanto, una violación de la Primera Enmienda. Sin embargo, la Jueza y el voto del Juez Bryer, que con ella concurre, aplica el triple test de Agostini y confirma, junto a la mayoría, que no puede demostrarse el adoctrinamiento religioso, ni que el Gobierno elija a los beneficiarios en función de la religión, y por lo tanto se sostiene la constitucionalidad de las ayudas ${ }^{113}$.

110 Mitchell, p. 2541-2545. Vid. Agostini, 226.

111 Michell, p. 2556-2568.

112 Mitchell, p. 2560.

113 Aplica los criterios recogidos en Agostini con los siguientes términos: “(1) whether the aid results in governmental indoctrination, (2) whether the aid program defines its recipients by reference to religion, and (3) whether the aid creates an excessive entanglement between government and religion", Mitchell, p. 2560. 
El voto particular en el fallo es del Juez Souter, con quien concurre los Jueces Stevens y Ginsburg. Su principal objeción a la mayoría es la reducción del test de constitucionalidad a un único aspecto de la neutralidad. Este contenido del concepto de neutralidad, en su opinión ${ }^{114}$, ha sido tergiversado en la década de los ochenta. Si bien, en un principio, la "neutralidad» aludía a la prohibición de beneficios religiosos, hoy en día, significa el acto "justo" neutral por el cual se distribuye beneficios, desde un punto de vista aséptico e igualitario entre todos los solicitantes. Sin embargo, este contenido del concepto de neutralidad no es suficiente ni agota el análisis del impacto constitucional de las ayudas a las escuelas. Es necesario señalar otros tres tipos de problemas en la distribución y asignación de las ayudas.

El primero consistirá en analizar si la escuela tiene un objetivo $y$ un carácter claramente religioso. Si así es, el profesorado difícilmente podrá eludir en su enseñanza una impronta religiosa y, por lo tanto, las ayudas gubernamentales indirectamente estarán ayudando o sosteniendo la religión que ostenta el personal del colegio ${ }^{115}$. En segundo lugar, es necesario estudiar el carácter, directo o indirecto, de estas ayudas. La jurisprudencia ha considerado que las ayudas directas son peligrosas al comprometer la naturaleza neutral del Estado; además, cualquier ayuda apareja un sistema de control estatal de la ayuda directa prestada que viola igualmente la independencia de las instituciones religiosas ${ }^{116}$. Al examinar el carácter de las ayudas, el Tribunal afirma que no sólo estarán prohibidas cuando estén destinadas a usos religiosos, sino también cuando las circunstancias en que se prestan las ayudas conduce al destino religioso de las mismas ${ }^{117}$. Por lo tanto, estima el Juez Souter, las ayudas monetarias

\section{J. Souter, Mitchell, p. 2579-2581.}

115 El problema se agrava cuando las escuelas son de primaria o de secundaria. El Juez Souter toma de precedente Lemon v. Kurtzman para indicar que el nivel de madurez de los estudiantes de estos colegios difiere notablemente con el de aquellos estudiantes de universidad o college, de modo que merecen una atención especial en el análisis de la Establishment Clause: "older students are more likely to be skeptical of instructors, and they are more able to separate religious from no-religious beliefs (...) also, religious affiliated universities, as opposed to primary and secondary schools, allow a great deal of academic freedom and sep to evoke critical responses from students", J. Souter, Mitchell, p. 2582-2583.

$116 \mathrm{~J}$. Souter recapitula jurisprudencia anterior y sostiene que "direct aid raises a greater risk of running afoul of the ban on government's participation in religion» (...) indirect aid that a religious school receives as a result of genuinely independent and private choices of aid recipients is constitutional" y cita Witters v. Wash. Dep't of Servs. for the Blind, 474 U.S. 481,187 (1986).

117 " (...) aid is invalid when circumstances would allow its diversion to religious use", Mitchell, 2585. Esta afirmación del J. Souter la sostiene en los argumentos jurídicos vertidos en Everson. 
se consideran inconstitucionales por la facilidad en que puede pervertirse su destino, en principio, secular. Por último, si se autoriza las ayudas a escuelas privadas de carácter religioso es probable que se empleen no solo en la instrucción educativa sino también en el adoctrinamiento religioso.

En conclusión, los votos particulares discrepantes a través el razonamiento del J. Souter, consideran el fallo de la mayoría equivocado al haberse fundamentado en tres suposiciones erróneas. La primera consiste en haber fundamentado los posibles efectos inconstitucionales de las ayudas estatales en la apreciación de dicha constitucionalidad por parte de un "observador imparcial»; la segunda, la creencia que el reparto igualitario de las ayudas desencadena efectos iguales para todos los beneficiarios; $y$ la tercera, la afirmación que una concesión de ayudas basadas en criterios de asistencia o números de alumnos salvaguarda la independencia del colegio, del igual modo que cuando las ayudas se destinan a los padres. A continuación, el Juez Souter analiza el Capítulo 2, tal y como es aplicado en Jefferson Parish, y aprecia varias causas de inconstitucionalidad ${ }^{118 .}$

\subsubsection{Los efectos de Mitchell v. Helms}

Si bien la intención de Mitchell ha sido la de prevenir discriminaciones y reordenar los posibles privilegios que hacían acreedores a ciertos grupos de beneficios en clara ventaja comparativa al resto, el principio de neutralidad que introduce Mitchell conlleva ciertas complejidades de difícil solución. Un ejemplo de las mismas ya la adelantó el juez Brennan en Lemon v. Kurtzman «cualquier institución que recibe ayuda financiera estatal queda obligada por la Equal Protection Clause de la decimocuarta enmienda al principio de no-discriminación en todo lo referente a las politicas de contratación” 119. Por lo tanto, las escuelas religiosas que reciban ayuda estatal se encontrarán con ciertos problemas cuando decidan llevar

118 1. El programa de la Jefferson Parish permite el desvío de los fondos públicos en escuelas privadas claramente religiosas (Mitchell, p. 2591); 2. El equipo destinado a las escuelas religiosas no es para uso individual de los estudiantes (Mitchell, p. 2592); 3. Los requisitos en el Capítulo 2 para concretar el destino que se les da a las ayudas vienen establecidos por personal de los colegios y por los padres y no por personal secular (Mitchell, p. 2592); 4. Las medidas de precaución para evitar que el destino de los fondos suponga una violación de la cláusula de no establecimiento son insuficientes (Mitchell, p. 2593); 5. El programa de control y supervisión sobre la dirección de las ayudas es deficiente (Mitchell, p.2594). Además, no se ha mantenido ninguna justificación ni informe sobre los materiales adquiridos mediante el Capitulo 2 (Mitchell, p. 2594 ).

119 Lemon v. Kurtzman, 403 U.S. 602, (1971) 651. 
a cabo sus prácticas contractuales: ¿qué ocurrirá si la solicitud de trabajo de un profesor de religión islámica para un colegio judío, financiado con fondos públicos, es denegada por motivos religiosos? ${ }^{120}$. Otro buen ejemplo de la dificultad del principio de "neutralidad formal» que avanza Mitchell consiste en la determinación de los criterios que la Administración considera convenientes para la adjudicación de las ayudas. Estos criterios pueden fácilmente adolecer de un sesgo parcial, es decir, el sesgo de la mayoría. Anteriormente se señaló que Smith fue la medida por la que se pudo apreciar hasta dónde los tribunales estaban dispuestos a sostener una ley neutral y mayoritaria frente a las pretensiones de minorías poco reconocidas. Con este antecedente, es posible que el Gobierno encuentre maneras de restringir la financiación o la participación en programas públicos a grupos como los Wicca, la Iglesia de la Cienciología o los Kirshnas porque lo demande la opinión pública ${ }^{121 .}$

Además de estas dificultades, el voto mayoritario y plural de la mayoría viene a reforzar el principio jurídico de la uneutralidad formal» que se utilizó en Smith, mediante el cual, la procedencia y conocimiento de los beneficiarios de la protección de la primera enmienda es irrelevante a efectos de la adjudicación por igual de ayudas o garantías a todos los beneficiarios y titulares. Frente a esta interpretación del principio de neutralidad se desarrolla una alternativa conocida como la "neutralidad sustantiva". Ésta viene a ser una corrección de las consecuencias de la neutralidad formal que no había atendido a los efectos de las acciones de la Administración o del Gobierno y consiste - como apunta Monsma- en "atender si la acción del Gobierno tiene el efecto de incentivar o desincentivar a las personas a seguir unas creencias determinadas»122, responsabilizando al Gobierno de las consecuencias de sus acciones. Si se hubiese

120 Derek H. Davis se plantea otras preguntas semejantes: «What about the student whose application to a religious school is rejected for religious reasons and whose parent come to realize that their tax money now subsidizes certain "secular « functions of the school that rejects their child? Or perhaps a school that accepts government aid through one or more programs governed by the neutrality principle even though its teachers do not meet government certification standards and its students consistently fail to meet minimum standards on college entrance exams? Does the government intervene in such a case to ensure a proper return on its investment?", D. H. DAVIS, "Mitchell v. Helms..." cit. pág. 1053.

121 Vid. Church of the Lukumi Babalu Aye v. City of Hialeah (1993). En Texas, un ministro del grupo religioso Wicca fue invitado a recitar una oración de apertura de una reunión del pleno del ayuntamiento. Los asistentes protestaron y algunos fueron detenidos por agresiones al ministro de culto. Vid. J. FLOYD, "Why All the Intolerance, Pray Tell?, Dallas Morning News, 5 de octubre de 2000, pág. 29A.

122 S. MONSMA, "Substantive Neutrality as a Basis for Free Exercise-no establishment Common Ground", Journal of Church and State, vol. $42 n^{\circ} .1$ (2000) pp. 13-35 en 
utilizado el principio de la neutralidad sustantiva en Mitchell, hubiese sido necesario demostrar que la ayuda provista mediante el capítulo 2 incentivaba o desincentivaba la práctica religiosa. Es muy posible que el fallo hubiese sido el mismo pero hubiese sido necesario incorporar un análisis más detallado del destino que llevaban las ayudas. En todo caso, este planteamiento del principio de neutralidad conlleva problemas cuando las ayudas están destinadas a servicios sociales o a la prestación de bienes de interés público cuyos agentes 0 actores son grupos religiosos puesto que la finalidad no es religiosa pero la gestión y el titular que lo disfruta sí lo es. Si se acepta que la Primera Enmienda debe proteger y amparar las actividades que desarrollan grupos seculares para el desempeño de sus fines cuando concurran públicamente con grupos religiosos, sin posibilidad de exclusión por el principio de no-discriminación, nos encontrariamos con una ampliación de la protección de la Primera Enmienda que sin duda llevaría a su distorsión, a no ser que se consiguiera definir lo que es un grupo religioso; empresa, en todo caso, de dudoso resultado ${ }^{123}$.

En cualquier caso, el fallo de la sentencia Mitchell no sorprendió en exceso a los especialistas del estudio de la Primera Enmienda puesto que el mismo Presidente George J. Bush había realizado declaraciones sobre la conveniencia de subsidiar a las organizaciones de corte religioso, asi como la necesidad de prestar un mayor control gubernamental a los fondos públicos destinados a las mismas ${ }^{124}$. La primera de las consecuencias de esta política es la pérdida de autonomía y la privación de la independencia de los grupos religiosos ${ }^{125}$.

pág. 27. El autor se hace eco de planteamientos de D. Laycok y M. McConell. Laycok ha desarrollado el concepto de "sustantive neutrality" con las siguientes palabras: "My basic formulation of substantive neutrality is this: the religion clauses require government to minimize the extent to which it either encourages or discourages religious belief or disbelief, practice or nonpractice, observance or no observance» en D. HAYCOCK, "Formal, Substantive, and Disaggregated Neutrality Towards Religion", DePaul Law Review, vol. 39 (1990) pp. 993-1018 en pág. 1001. Por su lado McConnell ha escrito: "My position is that the government must 'single out' religion in both free exercise and establishment contexts, with the goal of approximating a substantive neutrality in a religiously pluralistic culture" en M. MCCONNELL, "Accommodation of Religion..." cit. pág. 719.

123 Para un análisis de los problemas del principio de neutralidad sustantiva, vid. Ibíd. pp. 28-33.

124 Vid. M. LACEY y L. GOODSTEIN, «Bus Fleshes out details of proposal to expand aid religious organizations", New YorkTimes, 31 de enero (2001) pág. A15.

125 Para un análisis de las consecuencias sobre la autonomía de los grupos religiosos de la sentencia Mitchell, vid. D. DAVIS, op. cit. pp. 1054-1068. 


\subsubsection{Los límites de la libertad religiosa: Santa Fe Independent} School District v. Doe

El juego de las dos cláusulas de la Primera Enmienda norteamericana alcanza un grado aún mayor de complejidad cuando en él concurren las garantías que esta misma enmienda concede a la libertad de expresión. Considerada como una de las principales libertades consagradas en la Constitución americana, el derecho de cualquier ciudadano creyente a la libre expresión de las creencias religiosas puede verse comprometido si el Gobierno no permite su libre desarrollo en lugares públicos, tales como los recintos escolares, bajo el argumento de la peligrosidad para la Primera Enmienda que conlleva promover un determinado discurso religioso. En el caso que pasamos analizar a continuación, el TS perdió la oportunidad de proveer a los tribunales de un criterio uniforme y vinculante para analizar el problema de las prácticas religiosas en el contexto escolar, y añadió mayor confusión a la hora de elegir el escrutinio de constitucionalidad más oportuno para analizar la violación de la cláusula de no establecimiento. Antes de proceder al estudio de Santa $F e$ y de su posterior influencia, es necesario recordar brevemente los diferentes escrutinios constitucionales que la jurisprudencia ha venido utilizando para la cláusula de no establecimiento en litigios escolares.

\subsubsection{Antecedentes y precedentes de Santa Fe.}

El estudio de los casos de la enseñanza y la libertad religiosa, a la luz de la Primera Enmienda, comienza en 1947 con Everson v. Board of Education of Ewing ${ }^{126}$. En esta decisión, el TS concretó el contenido de la cláusula de no establecimiento a la luz de la doctrina estricta de no-ayuda a las instituciones religiosas ${ }^{127}$. Quince años después, se utilizó la teoría de la no-ayuda para cuestionar la constitucionalidad de las oraciones escolares en la enseñanza pública en Engel v. Vitale128. En este caso, elTS consideró tales actividades transgresoras de la cláusula de no establecimiento: "en este país, no es competencia del Gobierno componer oraciones oficiales para ser recitadas por un grupo determinado de americanos en el

126 Everson v. Board of Education of Ewing, 330 U.S. 1, 15 (1947).

$127(\ldots)$ the First Amendment has erected a wall between church and state and that wall must be kept high and impregnable, lbíd. 16.

128

Engel v. Vitale, 370, U.S., 421 (1962). 
marco de un programa religioso llevado a cabo por el Gobierno» 129. Además, el Tribunal estimó que «uno de los mayores peligros del derecho de libertad religiosa individual a la observancia de ciertas oraciones es que el Gobierno selle oficialmente con su aprobación unas prácticas determinadas o una forma particular de observancia del cultos ${ }^{130}$. No es relevante para elTribunal si dichas prácticas son neutrales o su observancia voluntaria puesto que la cláusula de no establecimiento se sostiene sobre «la creencia que la unión del Gobierno y la religión tiende a destruir y a degradar la religión" ${ }^{131}$. Sólo un año después, el TS completa y refuerza los argumentos jurídicos de Engel en School of District of Abington $v$. Schempp ${ }^{132}$, donde se examinan los programas de lectura voluntaria de la Biblia, Lord's Prayers, con carácter también voluntario para los alumnos. A pesar de esta voluntariedad, elTS estimó que se favorecía y se producía un avance de la religión $y$, por tanto, se violaban los principios de separación y neutralidad entre el Gobierno y la religión ${ }^{133}$.

Desde Everson, el TS ha formulado y asentado jurisprudencialmente tres escrutinios constitucionales para analizar y aclarar los conflictos surgidos en torno a la cláusula de no establecimiento. El primero se conoce como Lemon test por alusión al caso Lemon v. Kurtzman ${ }^{134}$ (1971) y se establece formalmente el triple criterio desarrollado por el Supremo a lo largo de los años para valorar jurídicamente las cuestiones de asistencia estatal financiera ${ }^{135}$. La jurisprudencia no ha seguido los tres criterios conjuntamente; a veces, se ha seguido sólo uno de ellos y, en ocasiones, se han rechazado todos ${ }^{136}$. El segundo escrutinio de constitucionalidad tiene su origen en el trascendente voto particular concurrente de la Juez

129 Ibid. 425.

130 Ibid. 429.

131 Ibid. 431

132 School of District of Abington v. Schempp, 374 U.S. 203 (1963).

133 Se vuelve a repetir: "the first and most immediate purpose of the Establishment Clause rested on the belief that a union of government and religion tends to destroy government and to degrade religion", Schempp, 221. Vid. G. MORÁN, La protección jurídica..., cit. pp. 64-66

134 Lemon v. Kurtzman, 403 U.S. 602 (1971). Vid. G. MORÁN, La protección jurídica..., cit. pp 50-52.

135 Vid. las referencias anteriores en el epigrafe "Libertad religiosa en las dos cláusulas de la Primera Enmienda».

136 A modo de ejemplo, el Juez Scalia en Lamb's Chapel v. Center Moriches Union Free School District, 508 U.S. 384 (1993) sostenía: “(...) Like some ghoul in a late-night horror movie that repeatedly sits up in its grave and shuffles abroad, after being repeatedly killed and buried, Lemon stalks our Establishment Clause jurisprudence once again", 398. 
$O^{\prime}$ Connor en Lynch $v$. Donnelly ${ }^{137}$ que creó el conocido "endorsement test», por el que se reduce el estudio de la violación de la cláusula de no establecimiento al análisis de la intención del Gobierno de respaldar o desaprobar una religión ${ }^{138}$. Posteriormente, elTS hace suyo el razonamiento de la Jueza O'Connor en County of Allegheny v. American Civil Liberties Union ${ }^{139}$ y el magistrado ponente lo desarrolla en los que serán los principios interpretativos para los casos de la cláusula de no establecimiento: 1. cualquier respaldo gubernamental de una religión es inconstitucional porque envía un mensaje de exclusión a los no-creyentes; 2 . el efecto que desencadena cualquier demostración de corte religioso dependerá de la evaluación que haga del mismo un observador imparcial140. Por último, tal y como se mencionó al inicio de este trabajo, el tercer escrutinio se elabora en el precedente más inmediato de Santa Fe, Lee v. Weisman ${ }^{141}$, y se conoce como el "coercion test".

En Lee, elTS analizó si la actuación de ministros de culto que ofician oraciones en las ceremonias de graduación vulneraba las cláusulas de la Primera Enmienda. El sistema escolar en Providence, Rhode Island, permitía a los directores de los centros escolares invitar a ministros de algunas confesiones a bendecir las ceremonias de graduación. El director, Robert $\mathrm{E}$. Lee, invitó a un rabino a bendecir la ceremonia bajo condición de que lo hiciera de manera "no confesional". La asistencia al acto público escolar era voluntaria. EITS no entró siquiera a considerar el Lemon test, dada la claridad con la que se apreciaba la relación Estado-religión 142 , y se detuvo en el efecto de la ceremonia en los estudiantes. ElTribunal rechazó el argumento formalista de que la asistencia era voluntaria, reconoció la relevancia e importancia de la ceremonia de graduación, tanto para los padres

137 Lynch v. Donnelly, 465 U.S. 668 (1984). En este caso, la autoridades municipales adquirieron un belén, cuya instalación suponía un coste para el municipio. El Tribunal de distrito y el de Apelación sostuvieron la violación de la cláusula de no establecimiento y elTS la contraria.

138 " (...) the proper inquiry under the purpose prong of Lemon is whether the government intends to convey a message of endorsement or disapproval of religion (...) what is crucial is that a government practice not have the effect of communicating a message of government endorsement or disapproval", J. O'Connor, 691-692.

139 County of Alleghency v. American Civil Liberties Union, 492 U.S. 573 (1989).

140 Juez Blackmun, Ibíd. 595.

141 Lee v. Weisman, 505 U.S. 577 (1992).

142 " $(. .$.$) it is not part of the business of government to compose official prayers$ for any group of the American people to recite as a part of a religious program carried on by government", Ibid. 588 . 
como para los estudiantes, y sostuvo la inconstitucionalidad de estas prácticas debido la presión ejercida sobre los no creyentes ${ }^{143}$. En Lee, se describe por una escasa mayoría en nuevo escrutinio que aparecerá en los fundamentos de derecho de Santa Fe. Además, el TS utilizó dos de los criterios del Lemon test, lo que convierte Lee en una sentencia poco esclarecedora sobre los criterios definitivos para el análisis de la cláusula de no establecimiento.

Cuando en Santa Fe se defendió la constitucionalidad de las oraciones previas a los partidos de fútbol, se utilizó la protección constitucional de la cláusula de la libertad de expresión que protege todo discurso religioso realizado en espacios públicos. Esta situación tiene sus precedentes en la jurisprudencia del Tribunal Supremo que había analizado con anterioridad el conflicto que supone para la separación Iglesia-Estado la autorización de los discursos y las prácticas de contenido religioso en lugares financiados por el Estado. El primero de estos precedentes es Widmar v. Vincent ${ }^{144}$, en el que se presenta la cuestión relativa al igualitario acceso a las facilidades escolares. La Universidad Estatal de Missouri, en Kansas City, permitía la utilización de los edificios universitarios a diversas asociaciones estudiantiles, incluidas las religiosas. Durante cuatro años consecutivos, un grupo religioso llamado Cornerstone hizo uso de estas facilidades hasta que una nueva normativa prohibió las prácticas religiosas en los recintos universitarios. Se inició el proceso alegando violación del ejercicio de libertad religiosa $y$, a su llegada a instancia delTS, el Tribunal estimó que las restricciones que la universidad imponía a los grupos religiosos eran claramente discriminatorias. Al aplicar los criterios del Lemon test, el TS consideró que el cuestión litigiosa cumplía el primer y tercer criterio. En cuanto al segundo, el Tribunal explicó que la doctrina del "foro público" permite la libre expresión de las creencias religiosas, sin que por esto se favorezca la religión. Esta conclusión toma en consideración dos factores, especialmente relevantes: 1. un foro abierto en una universidad pública no conlleva «el sello estatal de aprobación de unas determinadas creencias" 145 y 2 . el foro estaba disponible para una amplia gama de grupos religiosos y no religiosos. Por lo tanto, no puede probarse que la consecuencia directa y primaria de la doctrina del foro público sea el sostenimiento de una religión.

143 " $(. .$.$) the sole question is whether a religious exercise may be conducted at$ a graduation ceremony in circumstances where young graduates who object are induced to conform", Ibíd. 599.

144 Widmar v. Vincent, 454, U.S. 263 (1981).

145 Ibid. 274. 
Años más tarde, en Board of Education v. Mergens ${ }^{146}$ elTribunal sostuvo que no violaba la Establishment Clause las actividades de un club de estudiantes cristianos reunidos, entre otras cosas, "para leer, discutir la Biblia y rezar» 147 en la escuela pública Westside High School. Según la Equal Access Act $^{148}$ todas las actividades extracurriculares estaban permitidas. Las actividades con carácter religioso concurren con el resto de actividades de tipo deportivo, filosófico y secular. La cuestión es si atenta contra la cláusula de no establecimiento que el Estado elija como beneficiario de las ayudas para estas actividades a los grupos religiosos. El Tribunal estimó que la exclusión de este grupo vulneraba la Equal Access Act y siguió la lógica jurídica de Widmar ${ }^{149}$. En su opinión, la prohibición que hace dicha ley contra toda discriminación de discursos políticos, filosóficos y religiosos es suficiente para reunir el primer criterio del Lemon test, además, como la ley permite un acceso igual a discursos bien seculares bien religiosos «el objetivo de la ley no es ni apoyar o desaprobar una religión" 150. El Juez Kennedy - ponente de la sentencia - señaló que al permitir las actividades extracurriculares religiosas no se está autorizando al colegio a exigir que los estudiantes participen en un club religioso o se les está obligando a acudir a él151. El amplio espectro de opciones preserva a los estudiantes de la coacción ambiental para participar en un determinado club religioso ${ }^{152}$. Por otro lado, los demandantes alegaron que la ley tenía como efecto la promoción de la religión y el TS contestó que "existe una diferencia crucial entre discursos estatales o gubernamentales que promueven una religión, prohibidos por la cláusula de no establecimiento y discursos a título particular de tipo religiosos, protegidos por las garantías del derecho a la libertad de expresión»153. Además, el Tribunal añadió que los estudiantes de secundaria tienen madurez suficiente para entender que el colegio no está apoyando un discurso religioso permitido por el

146 Board of Education v. Mergens, 496 U.S. 226 (1990).

147 Ibíd. 232.

148 Equal Access Act, 20 U.S.C. 4071 et. seq. (1994) prohibe: "public secondary schools that receive federal assistance and that maintain a 'limited open forum' from denying 'equal access' to students who wish to meet within the forum on the basis of the content of the speech at such meetings", Mergens, 496 U.S. 233.

149 Ibíd. 249.

150 lbíd. 248.

151 lbíd. 261.

152 De hecho, se incluian más de 30 clubs voluntarios: ajedrez, animadoras, corales, negocios, debates, latín, matemáticas, arte dramático. Ibíd. 231.

153 lbid. 250. 
principio de no-discriminación ${ }^{154}$. Mergens adquiere relevancia porque se señalan los criterios que se han ido desarrollando en los temas de educación religiosa en los centros públicos: 1 . Posibilidad de organización de esos cursos de formación religiosa tanto fuera como dentro del centro aunque no sea por el centro- 2. Siempre fuera del horario escolar y 3. Debe estar abierta esa posibilidad a todos los grupos religiosos y a los de naturaleza secular en igualdad de condiciones.

Tres años más tarde, el TS confirma las conclusiones de Mergens en Lamb's Chapel v. Center Moriches Union Free Distric ${ }^{155}$ e invalida una norma del distrito escolar que permitía el uso de las propiedades del colegio para actividades recreativas extra-escolares de tipo social y cívico, con exclusión explícita de las de tipo religioso ${ }^{156}$. Tanto el Tribual de distrito como el tribunal de apelación sostuvieron la constitucionalidad de la norma y elTS, sin entrar en la valoración de la constitucionalidad de la misma, utilizó el principio de no-discriminación para permitir las actividades de los grupos religiosos. EITS consideró que el miedo a una violación de la cláusula de no establecimiento era infundado puesto que, en primer lugar, las actividades no eran en horario escolar; en segundo lugar, no estaban patrocinadas por el colegio; $y$, tercero, no estaban dirigidas sólo a miembros de los grupos religiosos 157 .

En general, estos precedentes nos indican que elTS permite los discursos religiosos en el seno de las escuelas públicas, siempre y cuando, estén abiertos a todo tipo de oradores, así como a todo tipo de contenidos. Cuando los centros educativos alegan la posible excesiva relación entre el Estado y la religión como consecuencia de la autorización de estos discursos, el TS no aborda el problema desde el conflicto libertad de expresión y cláusula de no establecimiento sino que lo reconduce al principio de no discriminación, evitando, de este modo, cuestiones de mayor complejidad jurídica.

\subsubsection{Análisis de Santa Fe v. Doe}

El Distrito Escolar Independiente de Santa Fe ("SFISD») es un división administrativa de Texas responsable de la educación de más de cua-

154 Al respecto, el TS apuntó: " the broad spectrum of officially recognized student clubs at Westsite, and the fact that Westside students were free to initiate and organize additional student clubs counteracted any message or official endorsement of or preference for religion", Ibid. 251.

155 Lamb's Chapel v. Center Moriches Union Free District, 508 U.S. 384 (1993).

156 Ibid. 387.

157 lbíd. 395. 
tro mil estudiantes de una pequeña comunidad al sur del pais. Los demandantes son dos familias, una católica y otra mormona, que interponen demanda al colegio por violar la cláusula de no establecimiento en las actividades previas a la ceremonia de graduación. Acusan al colegio de promoción a la asistencia a reuniones baptistas, de persecución de los estudiantes pertenecientes a minorías y de apoyo para la afiliación a clubs religiosos. Además, alegan que la SFISD permite bendiciones cristianas y oraciones desde el estrado en las ceremonias de graduación.

El Tribunal de Distrito dicta una orden en la que especifica que las bendiciones sin carácter religioso serán presentadas por estudiante/s elegido/s seleccionado/s entre la misma clase aspirante a graduación, quienes también votarán el texto correspondiente al discurso-bendición. En respuesta a la orden del tribunal del distrito, el SFISD adoptó dos tipos de políticas: una para las ceremonias de graduación ( "July policy") y otra para los partidos de fútbol («August policy»). En ambas se dispone que los discursos no serán ni sectarios ni religiosos y la persona para llevarlos a cabo será la que resulte de una votación ${ }^{158}$. En agosto de 1995, los estudiantes eligen en votaciones separadas el contenido de la oración y el estudiante que la realizará y el SFISD incorpora la novedad del contenido religioso del discurso en otra "policy" conocida como la "October policy»159. El tribunal del distrito ordena la no implementación de esta política si no se excluye del contenido las alusiones religiosas. EI SFISD considera conforme a ley la "October policy" y las dos familias deciden apelar.

El tribunal del quinto Circuito analizó, entre otras 160 , las siguientes cuestiones: 1. si la conocida "July policy" tenía la única intención de solemnizar la ceremonia de graduación y, en consecuencia, reunía el requisito de secularidad del primer criterio del Lemon test ${ }^{161} ; 2$. si las políticas del SFISD favorecían y apoyaban a la religión ${ }^{162}$; 3 . si las políticas del SFISD violaban el coercion test ${ }^{163}$; y 4 . si el SFISD mediante la "July policy" estaba limi-

158 Santa Fe, 294-296.

159 Santa Fe, 298.

160 El tribunal del Quinto Circuito analizó otras cuestiones y tuvo en cuenta los precedentes de Santa $\mathrm{Fe}$ que se registraban en la jurisprudencia de este mismo tribunal, en relación con los discursos previos a las ceremonias de graduación y con anterioridad a los partidos de fútbol: Vid. Jones v. Clear Creek Independent School District, 977 f. 2 d. 963 (5th Cir. 1992) y Doe v. Ducanville Indep. Sch. Dist. 70 F. 3d. 402 (5th Cir. 1995).

161 Doe v. Santa Fe, 168 F. 3d 806. 815 (5th Cir. 1999), para diferenciar la sentencia delTribunal Supremo de aquella del tribunal del Quinto Circuito, a esta última, llamaré Doe.

162

163 Ibíd. 
tando el "foro público»164. En general, el tribunal utilizó un criterio mixto, basado en el Lemon test y en el endorsement test, para sostener que las políticas del SFISD no tenían un objetivo claramente secular y uno de sus principales efectos era apoyar y favorecer la religión ${ }^{165}$. En los fundamentos de derecho, el tribunal sostuvo que la doctrina del "foro público" y de la libertad de expresión no eran de aplicación al caso ${ }^{166}$.

EITS, en apelación, analizó si las oraciones iniciales a los partidos de fútbol violaban la cláusula de no establecimiento ${ }^{167}$. En la primera parte del análisis, el Tribunal utilizó el coercion test (descrito en Lee) para determinar si la "October policy" vulneraba la cláusula de no establecimiento ${ }^{168}$. Antes de proceder a semejante estudio, se analizó si los mensajes de la "October policy" tenían una naturaleza privada o pública. El Tribunal rechazó el argumento del SFISD a favor de la naturaleza privada de los discursos, puesto que el colegio sólo permitía a un estudiante elegido por un periodo de un año realizar la bendición ${ }^{169}$. Además, dado que el sistema permitía al SFISD designar el contenido apropiado por un sistema de votación mayoritaria, las minorías se verían consecuentemente excluidas ${ }^{170}$. En la segunda parte del razonamiento jurídico, el Tribunal aclaró que las políticas del colegio vulneraban la cláusula de no establecimiento puesto que las dos subsiguientes elecciones, con los debates precedentes, trataban el tema religioso en las "urnas»; es decir, se producia una intromisión en las creencias religiosas al tiempo que dividían al alumnado171. Por otra parte, el carácter voluntario de estas actividades extracurriculares no deja

164 Ibid. 819.

165 “(...) Having concluded that student-selected, student-given, sectarian, proselytising invocations and benedictions at high school graduation violate both Lemon test and the endorsement, we are not required to determine that such public school prayer policies also run afoul of the coercion test to hold them antithetical to the Establishment Clause", Doe, 168 F. 3d. 818.

166 Ibid. 821.

167 Santa Fe, 530 U.S., 301 y ss.

168 EI TS utilizó los razonamientos jurídicos de Lee aunque los supuestos de hecho eran distintos: "our analysis is properly guided by the principles that we endorsed in Lee", Ibíd. 301.

169 “(..) selective access does not transform government property into a public forum". lbíd. 303.

170 El Tribunal apuntó: “the majoritarian process implemented by SFISD guarantees, by definition, that minority candidates will never prevail and that their views will be effectively silenced", Santa Fe, 303.

171 “(...) it encouraged divisiveness along religious lines in public school setting", Santa Fe, 370. 
a salvo a los alumnos que no conforman la mayoría del dilema entre acudir a los eventos deportivos o preservar los sentimientos religiosos de posibles ofensas 172 . Por último, en la tercera parte, elTS examinó la finalidad secular de la "October policy" a la luz del Lemon test y sostuvo la inconstitucionalidad del objetivo de la misma173.

\subsubsection{La influencia posterior de Santa Fe.}

EITS utilizó principios y escrutinios diferentes sobre la cláusula de no establecimiento en los diferentes razonamientos jurídicos a lo largo de la sentencia, sin coordinarlos ni confirmar uno de ellos como el más apropiado. En primer lugar, elTS comenzó señalando «nuestro análisis se guiará literalmente por los principios que se establecieron en Lee»174. A continuación, el Tribunal estimó que clas realidad de la situación claramente revela que las políticas del centro escolar implican un 'endorsement' de la religión"175. Y más adelante, el Tribunal concluye "como en casos anteriores que versan sobre la cláusula de no establecimiento, nosotros sostenemos la constitucionalidad de los tres criterios articulados en Lemon $v$. Kurtzmanı176. Con esta última afirmación cualquier lector se pregunta de qué han servido los razonamientos jurídicos que la han precedido.

En general, la mención de los diferentes escrutinios en la sentencia ha provocado un aumento de la confusión en el resto de los tribunales inferiores que esperaban un definitiva y necesaria claridad y uniformidad para los litigios de los discursos religiosos en los centros escolares. Con posterioridad, en Chandler v. Siegelman ${ }^{177}$, el TS confirmó la sentencia del Tribunal del undécimo Circuito que declaró inconstitucional una ley de Alabama que

172 Santa Fe, 312.

173 EITS consideró: 1. el lenguaje usado por esta política del colegio demostraba la interferencia del colegio en el nombramiento del orador y en el contenido de la misma; 2. el texto del discurso o invocación versaba sobre una religión tradicional; 3 . el acceso selectivo, así como otras restricciones, demostraba que la normativa o política no tenía una naturaleza neutral y creaba un foro público limitado. Por lo tanto, el Tribunal concluye que la política era inválida porque: "it establishes an improper majoritarian election on religion, and unquestionably has the purpose and creates the perception of encouraging the delivery of prayer at a series of important schools events", Santa Fe, 314.

174 Santa $\mathrm{Fe}, 301$.

175 Santa Fe, 305.

176 Santa Fe, 307.

177 Chandler v. Siegelman, 230 F. 3d, (11th Cir.)1314; 530 U.S. 1256 (2000). 
permitía oraciones, invocaciones y bendiciones, ni sectarias ni proselitistas, al comienzo de los eventos deportivos, de las asambleas colegiales o de las ceremonias de graduación ${ }^{178}$. El Tribunal de Circuito sostuvo que «las oraciones prohibidas en el caso Santa $F e$ eran coercitivas porque no eran privadas» 179 y, a continuación, apuntó "en Santa Fe se sostiene que sólo aquellas que sean promocionadas o sostenidas por el Estado y, además, coercitivas serán prohibidas por la Constitución» 180 . De acuerdo con este razonamiento parece que hubiese sido únicamente éste el argumento en Santa Fe y que el Tribunal acudiese exclusivamente al escrutinio de la coerción y no al "endorsement». Además, parece que el mensaje para los tribunales inferiores es el de ignorar el análisis del foro, bien público o privado ${ }^{181}$.

Un año más tarde, elTS añadió aún más confusión a la problemática de las oraciones en centros escolares públicos. El 10 de diciembre de 2001, el TS rechazó cuestionar la constitucionalidad de las conclusiones de Adler v. Duval County School Board 182 del Tribunal del undécimo Circuito, el cual confirmó una política educativa de un distrito de Florida que permitía a los estudiantes que se graduaban votar la conveniencia de oraciones a cargo de los mismos al inicio de la ceremonia de graduación. En Adler, el Tribunal de Circuito consideró que la "Duval policy" presentaba rasgos diferenciados de Santa Fe porque no involucraba a funcionarios del colegio; puesto que eran los mismos estudiantes los que elegían el contenido de las oraciones ${ }^{183}$. A mi parecer, y siguiendo el razonamiento del Juez Souter en Santa $\mathrm{Fe}$, aunque las oraciones sean el resultado de una elección que realizan los estudiantes, este hecho no sitúa este caso al margen de la cláusula de no establecimiento ${ }^{184}$. Quizás la manera de reducir la posible inconstituciona-

178 Chandler v. Siegelman, 230 F. 3d, (11th Cir.) 1317.

179 Chandler v. Siegelman, 230 F. 3d, (11th Cir.)1315.

180 Ibíd.

181 Para un análisis de esta sentencia: R. SCHMIERER, “An attempt to pick up the fallen bricks of the wall separating church and state after Santa Fe v. Doe", Brooklyn Law Review, vol. 67 (2002) pp. 1292-1342, pág. 1334.

182 Adler v. Duval County School Board, 122 S. Ct. 664 (2001); Adler, 250 F.3d. 1330 (11th Cir. 2001). Para un análisis de Adler, vid. M. A. BILLS, “Let us pray?:The Constitutionality of student-led graduation prayer after. Santa Fe v. Doe," University of Illinois Law Review (2002) pp. 149-184 en pp. 180-181.

183

Adler, 250 F.3d. 1337-1338.

184 El Juez Souter en sus argumentos orales en Santa Fe apuntaba: " if the student who is cosen exercises that student's choice to pray, we are still faced with a system in which it is the school or the school district that provides the forum in which this is going to appear, requires the attendance of a certain number of students to be there and, therefore requires those students to sit there while a prayer is going on. What more do we need to decide the Establishment Clause cases?, Fase oral, p. 17 vid. comentario en R. SCHMIERER, op. cit, pág. 1335. 
lidad al amparo de la cláusula de no establecimiento sea la de establecer criterios seculares en la selección de los estudiantes que intervendrán en las oraciones o invocaciones y que sean ellos los que elijan el discurso sin la supervisión ni intervención de la autoridades educativas ${ }^{185}$.

Concluyendo, el fallo de Santa $F e$ tuvo sus efectos, tanto jurídicos como políticos, de manera inmediata. Por lo que respecta a los primeros, a pesar de las críticas que siempre levantó el test Lemon, la mayoría de los magistrados vuelve a utilizarlo en los argumentos jurídicos. Además, retoman también los escrutinios del "coercion" y "endorsement" de modo que, hoy en día, abogados y jueces utilizan indistintamente o acumulativamente los tres escrutinios. Con la sentencia Santa Fe se pone fin a la cuestión de las oraciones elegidas mediante votación por los estudiantes. Esto puede apreciarse en la posición del Juez Kennedy que siempre mantuvo una postura oscilante en los litigios de la cuestión religiosa. En este caso, no sólo coincide con la mayoría sino que afirma que "debe evitarse que las escuelas se conviertan en foros para el debate religioso" ${ }^{186} \mathrm{y}$, más adelante, refuerza su posición: "permitir elecciones en los centros escolares para decidir la ejecución o no de oraciones es algo de lo que debe mantenerse alejada nuestra cláusula de no establecimiento "187. Desde el punto de vista político, Santa Fe tuvo gran impacto en la opinión pública. Un sector de la población americana se identificó con las conclusiones de la sentencia ${ }^{188}$ y otro gran sector denunció de la postura delTS ciertos prejuicios y una hostilidad evidente hacia las manifestaciones religiosas 189 . Como resultado de la polémica, se ha venido alentando las oraciones espontáneas del público asistente a los partidos de fútbol, las cuales estarían prote-

185 De hecho es la línea que sugiere el Juez Souter en Lee y la que se sugiere en Chandler: "student religious speech must be without oversight, without supervisión, subject only to the same reasonable time, place, and manner restrictions as all other student speech in school", Chandler v. Siegelman, 530 U.S. 1256 (2000) 1264-1265. Vid. al respecto, T.C. MATTOCKS, “Reflections on Santa Fe v. Doe: is student prayer at graduation still an option?",West's Education Law Reporter, vol. 333 (2001)pp. 150-184 en pág. 183.

186 Vid. L. GREEHOUSE, "Court Seems Reluctant to Allow Prayer at High School Ball games", New YorkTimes, 30 de marzo de 2000, pág. A24.

187 M. WALSH, "Court Hears Arguments in Prayer Case", Educational Week, 5 de abril de 2000, pág. 27.

188 "According to an $A B C$ News poll, two thirds of Americans supported Santa Fe's football prayer policy...",Your School and the Law, vol. 30, núm. 134, 7 de Julio de 2000.

189 Vid. D. SCHIMMEL, “Court outlaws school-sponsored students prayer: an analysis of Santa Fe v. Doe",West's Education Law Reporter, núm. 150 (2001) pp. 1-14 en pág. 13. 
gidas por la cláusula del derecho a la libertad de expresión. La dudosa espontaneidad de estas oraciones, así como el posible apoyo implícito del colegio donde se celebra el evento deportivo son cuestiones que no han abordado aún los tribunales.

\section{CONCLUSIÓN: LA POLÉMICA CONTINÚA}

La finalidad, contenido e interpretación de la cláusula de no establecimiento no ha dejado de ser objeto de litigios y discusiones doctrinales en los últimos cincuenta años. A diferencia de la cláusula de libre ejercicio, que tampoco ha estado exenta de polémica, la de no establecimiento ha generado mayor confusión como resultado de las numerosas elaboraciones doctrinales que el poder judicial ha utilizado indistintamente, en ocasiones, incluso en los fundamentos de derecho de una misma sentencia. Además de esta simultaneidad de criterios de interpretación, en el estudio que se ha desarrollado en estas páginas puede apreciarse una evolución temporal de los modelos principales de interpretación: de un modelo "de libertad", inspirado en los padres de la Primera Enmienda, a un modelo de "igualdad" que se desarrolla a partir de los años cincuenta y se confirma con la sentencia Mitchell.

Cuando la cláusula de no establecimiento quedó incorporada a los estados federados en la sentencia Everson de 1947, el Juez Black entrevió la intencionalidad de los Framers al redactar la Primera Enmienda: la eliminación de las persecuciones religiosas y la consecución del ideal de la libertad religiosa 190 . Aunque en el razonamiento del Juez Black no se mencionara literalmente a los grupos religiosos, un año más tarde, el Juez Frankfurter en McCollum v. Board of Education 191 reinterpretó las palabras del Black y articuló lo que más adelante se conocería como el escrutinio del "endorsement test" para la cláusula de no establecimiento: la cláusula protege a las minorias religiosas frente a la discriminación, la exclusión y la segregación social. Posteriormente, en 1962, el Juez Black en Engel amplió la interpretación de Frankfurter a las situaciones en las que el apoyo o impulso de toda religión por el Estado es perjudicial en sí misma conside-.

190

191

Everson, 30 US, p. 9.

McCollum v. Board of Education, 333 U.S. 203 (1948). 
rada aunque de la misma no derive efectos coercitivos para terceros ${ }^{192}$. Con esta interpretación, la protección de la libertad religiosa, que elevó el Juez Black en Everson a la intención prioritaria de los Framers, va quedando relegada a un segundo lugar puesto que no es necesaria una violación especifica de la libertad religiosa para apreciar una vulneración de la Primera Enmienda193.

Como se mencionó anteriormente, la Jueza O'Connor completó en los años ochenta la elaboración del "endorsement test» en Lynch sin mencionar la palabra "igualdad" a pesar de que se desprende fácilmente de su razonamiento. En su opinión, la intención de la cláusula fue la de hacer de la religión algo irrelevante a la comunidad política y evitar la exclusión de los ciudadanos por motivos religiosos, por lo tanto, cualquier apoyo o alianza entre el Estado y una religión determinada llevaría aparejada diferencias en el seno de la comunidad política, dividiría y, en último término, reduciría las posibilidades de igualdad real ${ }^{194}$. En Santa Fe - tal y como se apuntó - se menciona, tanto por la mayoría como por el Juez Rehnquist, el escrutinio del endorsement a la hora de valorar la constitucionalidad de los mensajes religiosos, quedando desplazado el escrutinio de la coerción. Lo más relevante de este caso es la dificultad e inconveniencia del principio de igualdad, consagrado en Mitchell, para valorar los litigios de los mensajes religiosos. Según el principio de igualdad, el valor inherente a proteger es el menoscabo o disminución de la igualdad, por lo tanto, siempre y cuando se compruebe esta disminución se confirmará la vulneración del derecho de libertad religiosa. En consecuencia, la vulneración podrá constatarse con independencia de la participación del personal de los centros escolares en la elección o en la proclamación de estas oraciones. De modo que la desventaja que sufrirían los grupos o individuos no se hacía depender del origen (bien estatal o privado) de estos mensajes que es, en definitiva, lo que viene a concluirse de la compleja sentencia Santa Fe. Con el endorsement, el análisis se centrará exclusivamente en la participación del Estado. Por el contrario, adoptando el escrutinio de la coerción, el derecho de libertad religiosa vendría protegido con indiferencia del origen de la

192 “The Establishment Clause, unlike the Free Exercise Clause, does not depend upon any showing of direct governmental compulsion and is violated by the enactment of laws which establish an official religion whether those laws operate directly to coerce non observing individuals or not", Engel v. Vitale 370 U.S. 421 (1962), 430.

193 Para una reflexión del cambio operado en los razonamientos del Juez Black en Everson y en Engel, vid. N. FELDMAN, "From Liberty to Equality: The Transformation of the Establishment Clause", California Law Review, vol. 90 (2002) pp. 673-731.

194 Ibíd. pág. 707. 
misma puesto que el análisis central pasaría a realizarse sobre los efectos provocados. A mi juicio, sólo si se adopta esta última línea argumentativa sería posible atender al análisis del principio de igualdad.

Por otra parte, la consagración del principio de igualdad como principal escrutinio de valoración para la cláusula de no establecimiento se ha consolidado en los litigios sobre las ayudas directas estatales a centros educativos privados. En Mitchell, como se ha apuntado en estas páginas, se sostiene que todas las ayudas -incluso directas - a instituciones religiosas pueden ser constitucionales siempre y cuando se mantengan accesibles a todo tipo de instituciones. A mi parecer, este enfoque presenta principalmente numerosas objeciones para la cláusula de no establecimiento. En primer lugar, niega ćualquier valoración específica o especial sobre el derecho de libertad religiosa. Si los Framers quisieron dotar a la religión de una protección específica con la Primera Enmienda, el principio de igualdad nivela todas las opciones posibles a un mismo tratamiento jurídico, restándole especificidad. En segundo lugar, la intervención igualitarista podría amputar autonomía e independencia a las instituciones religiosas, al quedar vinculadas al control y supervisión estatal. En tercer lugar, el igualitarismo anularía la justificación histórica y democrática a favor de la separación Iglesia-Estado.Y, en cuarto lugar, desde el punto de vista político, el subsidio gubernamental no sólo les resta a los grupos autonomía sino también vitalidad y dinamismo religioso.

Como he señalado es difícil emplear un único escrutinio constitucional para los litigios concernientes a la cláusula de no establecimiento, como también resulta de lo más arriesgado delimitar la finalidad de esta cláusula: ¿sería la libertad religiosa o la efectiva igualdad entre todos grupos con independencia de su carácter religioso?. Inicialmente, la intención de los Framers fue la de evitar que una religión oficial o nacional generara intolerancia e impidiera el libre ejercicio de la libertad religiosa de todos ${ }^{195}$. Sin embargo, también se pretendía evitar la preferencia de una religión sobre otra y este hecho no impidió la asistencia o la interacción entre religión y Gobierno ${ }^{196}$. Por lo tanto, la complejidad de interpretación y la dificultad del juego entre las dos cláusulas de la Primera Enmienda sur-

195 Así lo manifiesta el Juez Douglas en su opinión concurrente en School Dist. v Schempp, 374 U.S. 203, 221-223 (1962) y el caso Torcaso v. Watkins, 367 U.S. 488, 490 (1961).

196 Hay jurisprudencia que avala esta afirmación. Los Framers de las dos cláusulas religiosas en el Primer Congreso permitieron la relación del Estado con las iglesias, como las ayudas que hacian para las capillas. Vid. los casos: en relación con las 
gen desde sus inicios y se han mantenido hasta ahora. Teniendo en cuenta estos dos obstáculos, es decir, la complejidad y la dificultad de conciliación entre la libertad e igualdad religiosa197, así como la tendencia evidente hacia un enfoque "igualitarista» en la más reciente jurisprudencia norteamericana, las expectativas tendrán que situarse en un nuevo modelo que trate de coordinar el principio de igualdad con la corrección del principio de coerción que atienda, principalmente, a los efectos sobre la libertad de los individuos y de los grupos religiosos.

capillas y las vacaciones de Thanksgiving en Marsh v. Chambers 463 U.S. 783-788 (1952) y la opinión discrepante del Juez Rehnquist en Wallace v. Jaffree, 472 U.S. 38, 100 (1985). Para un comentario de esta opinión, vid. T. EASTALAND (ed.) Religious liberty in the Supreme Court, Ethics and Public Policy Center, Washington (1993) pp. 354-364.

197 En Everson se afirma que la neutralidad del Gobierno en materia religiosa quiere decir que las funciones del Gobierno y las religiosas no deben estar fusionadas y debe protegerse la libertad religiosa de presiones por parte del Estado, en 330 U.S. 1, 15 (1947). Vid. también el artículo de M. E. CHOPKO, "Intentional Values and the Public Interest, A Plea for Consistency in Church-State Relations, De Paul University Law Review núm. 39 (1990) pp. 1143-1186 :"Where the boundary between freedom and restraint is disputed, the first amendment is our only guide. It should not be trivialized by being overused or overstepped. The common good of the community of churches is best served by maintaining a set of conditions which assures our liberty to practice our various faiths in peace with the state and with each other. Those conditions are domestic tranquillity and stability, and strict obedience to the first amendment protection of personal religious freedom", en pág. 1173. Posteriormente, el TS en Agostini "tiende a declarar que la actuación estatal no conculca la Establishment Clause a menos que produzca una promoción pública de la religión o una coacción al individuo porque participe en una actividad religiosa", vi. J. R. POLO, op. cit. pág. 166. 